\title{
EVALUATION OF RENNET SUBSTITUTE FROM ARTICHOKE (Cynara scolymus L.) FLOWERS EXTRACTS: STUDY THE FACTORS AFFECTING THE ACTIVITY OF MILK CLOTTING
}

\author{
Heba-Allah H. Abdel-Raouf, A.A. El-Neshwy, A.M. Rabie and S.A. Khalifa ${ }^{*}$ \\ Food Sci. Dept., Fac. Agric., Zagazig Univ., Egypt
}

Received: 30/07/2017 ; Accepted: 18/09/2017

\begin{abstract}
Factors affecting milk clotting activity of rennet substitute extracted from green bracts of artichoke (Cynara scolymus) flowers in different buffer solutions were evaluated. These factors include extraction $\mathrm{pH}$, clotting temperature, extract concentrations, addition of $\mathrm{CaCl}_{2}, \mathrm{NaCl}$ and glucono delta-lactone (GDL) at different concentrations. The proteolytic activity of different extract solutions and rheological properties of produced curd was studied as well. The obtained results indicated that the optimum clotting activity of artichoke crude extracts improved water holding capacity and susceptibility to syneresis obtained at $\mathrm{pH}$ value of $5.0-6.0$, temperature of $65-70^{\circ} \mathrm{C}$ and $3 \%, 0.04-0.05,3 \%, 0.5 \%$ of crude extract, $\mathrm{CaCl}_{2}, \mathrm{NaCl}$ and GDL concentrations, respectively. The optimum clotting activity of artichoke crude extracts indicated that the sodium acetate buffer solution T4 (5\% NaCl in sodium acetate buffer, $\mathrm{pH} 5.0)$ and sodium phosphate buffer, $\mathrm{T} 5$ ( $5 \% \mathrm{NaCl}$ in sodium phosphate buffer, $\mathrm{pH} 5.5), \mathrm{T} 6(5 \% \mathrm{NaCl}$ in sodium phosphate buffer, $\mathrm{pH} 6.5)$, and $\mathrm{T} 7 \mathrm{(5 \%} \mathrm{NaCl}$ in sodium phosphate buffer, $\mathrm{pH} 7$ ). Results also indicated that artichoke crude extracted in sodium phosphate buffer solutions and sodium acetate buffer (T4) had higher proteolytic activity than other buffers. The best rheological properties of resultant curds were noticed in sodium phosphate buffers (T5, T6, T7) and sodium acetate buffer (T4).
\end{abstract}

Key words: Artichoke, Cynara scolymus, milk clotting activity, crude protein extracts, proteolytic activity, rheological analysis.

\section{INTRODUCTION}

Calf rennet is the most ancient known milk clotting enzyme and still the most widely used as biocatalyst in cheese making. The coagulating properties of calf rennet are related to the chymosin, an aspartic protease which considered the best coagulating agent thanks of its high specificity in cleaving the bond of $\kappa$ casein phenylalanine 105- methionine 106 bonds (Ahmed et al., 2009).

The worldwide increase in cheese production and consumption in the line with increasing the price of calf rennet led to search and investigate new sources of milk coagulating enzymes replacing calf rennet in cheese making (Guiama et al., 2010). Plant extracts, and various new vegetable sources of enzymes for milk clotting

\footnotetext{
* Corresponding author: Tel. : +201229931517
}

E-mail address: salahkhalifa2006@yahoo.com have been studied in recent years (Hashim et al., 2011).

The majority of these vegetable milk clotting enzymes belongs to the aspartic protease family (Simoes and Faro, 2004). Ficus carica (ElShibiny et al., 1973), Calm viscera (Gupta and Eskin, 1977), Ananas comosus (Cattaneo et al., 1994), and Carica papaya (Cabezas, 1981) were used as plant sources for the milk clotting enzyme. However, these enzymes are undesirable in cheese making because of their high proteolytic activity and bitterness of produced cheese (Ahmed et al. 2009).

Artichokes (Cynara scolymus L.) are perennial, frost sensitive, thistle-like plants with edible part known as flower buds, which sprout from the terminal part of the major stem and on lateral stems. Each unopened flower bud 
resembles a deep green pine cone, $7-10 \mathrm{~cm}$ in diameter, round, but slightly elongated. Several pointed, leathery green bracts fold around a purple-blue flower. Cynarases enzymes have been identified from artichoke (Verissimo et al. 1998), but because the flowers of this plant are usually consumed as a vegetable, the properties and possible applications of these cynarases are less known.

The use of flower extracts from Cynara genus and, in particular, of Cynara scolymus and Cynara cardunculus, is limited because of the multiplicity of aspartic protease molecular forms (Liorente et al., 2014).

Shah et al. (2014) used plant proteases in cheese making in the form of crude or purified extract for many centuries.

In general, the enzymes used as milk coagulant have aspartic proteases as an essential enzyme, while cysteine and serine proteases have been reported as well, thanks to their ability of milk clotting under specific conditions.

Proteases are required by plants in all aspects of their life cycle. Proteases have been classified into many groups based on their catalytic mechanism used during the hydrolytic process. The principle catalytic types are aspartate, serine, cysteine, and metalloproteases (Bah et al., 2006). Aspartic proteases have two main aspartic residues at their catalytic site. They are most active at acidic $\mathrm{pH}$ and show high preferential specificity for cleavage the peptide bonds between hydrophobic amino acid residues which are important for the catalytic activity (Domingos et al., 2000). It produces cardosins, cyprosins and aspartic proteases which found to be accumulated in only mature flowers (petals and pistils) (Cordeiro et al., 1998).

Cynarase isolated from artichoke (Cynara scolymus) has been reported in many previous studies for milk clotting activity as an aspartic protease with 2 aspartic acid residues at its catalytic site (Llorente et al., 1997; 2004; Sidrach et al., 2005; Chazarra et al., 2007).

The extract of $C$. scolymus contains three proteases (cynarases A, B and C), three cynarases are glycoproteins in addition to their milk clotting activity (Sidrach et al., 2005). The enzymes of coagulant activity may be decreased by the purification of plant extract compared to the crude extraction of cynarases A and C, however cynarase B increase its activity (Chazarra et al., 2007).

Therefore, the aim of the present study was to investigate the optimum extraction conditions of rennet substitute from the bracts of Cynara scolymus flowers and evaluating their clotting and proteolytic activity.

\section{MATERIALS AND METHODS}

\section{Materials}

\section{Skim milk powder}

Skim milk powder imported from USA extra grade, supplied by Egyptian Company for Dairy Products and Food Additives "EGY- DAIRY" $10^{\text {th }}$ of Ramadan city, Sharkia Governorate, Egypt, was used for the preparation of reconstituted skim milk that used for evaluating the activity of crude enzyme extract in milk clotting and proteolysis.

\section{Plant rennet}

Leathery green bracts fold around flowers of globe artichoke (Cynara scolymus L.) byproduct is the residue from fresh-handling and industrial processing of artichoke hearts was obtained from El Marwa for preserving and frozen vegetables and fruits El-Obour City, Egypt. These industries produce the type of artichoke byproducts: vegetable stuff composed of outer bracts. Fresh green bracts of artichoke flowers were dried at room temperature and hand crushed to obtain the powder.

\section{Methods}

\section{Protein extraction}

Plant crude protein extracts were obtained using homogenization under different conditions. About 100g of artichoke powder was reconstituted in $200 \mathrm{ml}$ of different buffers (Mohan, 2006) and homogenized by stirring at $4^{\circ} \mathrm{C}$. The used buffers were defined as follows: $\mathrm{T} 1=$ Distilled water, $\mathrm{T} 2=5 \% \mathrm{NaCl}$ in distilled water, $\mathrm{T} 3=5 \% \mathrm{NaCl}$ in sodium acetate buffer (pH 3.8), $\mathrm{T} 4=5 \% \mathrm{NaCl}$ in sodium acetate buffer (pH 5.0), $\mathrm{T} 5=5 \% \mathrm{NaCl}$ in sodium phosphate buffer ( $\mathrm{pH}$ 5.5), $\mathrm{T} 6=5 \% \mathrm{NaCl}$ in sodium phosphate buffer ( $\mathrm{pH} 6.5), \mathrm{T} 7=5 \% \mathrm{NaCl}$ in sodium phosphate buffer $(\mathrm{pH} 7), \mathrm{T} 8=5 \% \mathrm{NaCl}$ 
in Tris-HCl buffer (pH 8.0). Subsequently, the extract of each buffer was filtrated through cheesecloth and centrifuged at $1000 \mathrm{rpm}$ for 45 $\min$ at $4^{\circ} \mathrm{C}$ (Nouani, et al., 2009). The supernatant was collected and dialysed at $4^{\circ} \mathrm{C}$ against $0.1 \mathrm{M}$ sodium acetate buffer $(\mathrm{pH} 5.0)$ overnight (Ahmed et al., 2009).

\section{Evaluation of milk clotting activity}

Milk clotting activity was determined according to the method described by Ahmed et al. (2009). The substrate $(10 \%$ reconstituted skim milk in $0.01 \mathrm{M} \mathrm{CaCl}_{2}$ ) was prepared and the $\mathrm{pH}$ was adjusted to 6.5 . The substrate $(10 \mathrm{ml})$ was preincubated at different temperatures for $5 \mathrm{~min}$, the temperature was adjusted to $50^{\circ} \mathrm{C}, 55^{\circ} \mathrm{C}$, $60^{\circ} \mathrm{C}, 65^{\circ} \mathrm{C}$ and $70^{\circ} \mathrm{C}$ using a thermostatically controlled water bath. Briefly, 1, 2, 3, 4 and 5\% by volume of the crude extract was added into $10 \mathrm{ml}$ of the milk samples and unit of milk clotting activity (MCU) was determined by rotating the test tube at regular interval times and checking for visible clot formation on the wall of the test tubes. The following formula was used for calculating the milk clotting unit (MCU) (Nouani et al., 2009).

Unit of milk clotting activity $(\mathrm{U} / \mathrm{ml})=$ $(2400 / t) \times(S / E)$, where $t$ is the time required for clot formation, $\mathrm{S}$ is the volume of skim milk and $E$ is the volume of crude enzyme extract. The result was expressed as $\mathrm{MCU} / \mathrm{ml}$.

\section{The optimum conditions}

The optimum coagulation activity of enzymatic extracts was determined according to observing the required time for milk coagulation by varying the studied parameters. It is expressed as relative activity (\%) (Nouani et al., 2009).

\section{The optimum pH}

The optimum $\mathrm{pH}$ for milk coagulation using $3 \%$ of the crude enzyme extract was determined at different $\mathrm{pH}$ values 5-6.5 incubated at $65^{\circ} \mathrm{C}$. The $\mathrm{pH}$ value at which the milk coagulated in the shortest time was recorded as the $\mathrm{pH}$ optimum value required for milk coagulation using the plant extract.

\section{The optimum temperature}

A temperature range of $50-70^{\circ} \mathrm{C}$ was used to determine the optimum temperature for crude enzymatic activity using $3 \%$ of crude enzyme extract.

\section{The optimum concentration of $\mathbf{C a C l}_{2}$}

The optimum concentration of $\mathrm{CaC}_{2}$ was determined by observing the milk coagulation time watered down with $\mathrm{CaCl}_{2}$, at concentrations between 0.01 to $0.05 \%$ in a test tube incubated at $65^{\circ} \mathrm{C}$ with added $3 \%$ crude enzyme extract.

\section{The optimum concentration of $\mathrm{NaCl}$}

The optimum concentration of $\mathrm{NaCl}$ was determined by observing the milk coagulation time watered down with $\mathrm{NaCl}$, at concentrations between 1 to $10 \%$ in a test tube incubated at $65^{\circ} \mathrm{C}$ with added $3 \%$ crude enzyme extract.

\section{The optimum concentration of GDL}

The optimal concentration of Glucono-DeltaLactone (GDL) was determined by observing the milk coagulation time watered down with GDL, at concentrations between 0.1 and $0.5 \%$ in a test tube incubated at $65^{\circ} \mathrm{C}$ with added $3 \%$ crude enzyme extract.

\section{The optimum concentration of crude enzyme extract}

The volumes of crude enzymatic preparations added to the milk vary according to the suitable dilution factor of $1,2,3,4$ and $5 \%$ of crude extract in $10 \mathrm{ml}$ of milk in a test tube incubated at $65^{\circ} \mathrm{C}$.

\section{Measurement of proteolytic activity}

The proteolytic activity of coagulant extracts allows for the evaluation of the rate of the degradation rate of casein (Sigma, Biochemical, and reagents) during the primary reaction. It consists of measuring, the increase of nonprotein nitrogen (NPN) in trichloracetic acid (TCA) at $12 \%$ of the final mixture (Nouani et al., 2009). Briefly, $3 \mathrm{ml}$ of crude enzyme extract was added to $10 \mathrm{ml}$ of $3 \%$ degradation of casein (pH 6.5) in a test tube and incubated at $65^{\circ} \mathrm{C}$ for 1, 2, 3, 4, 5 and 6 hours.

\section{Rheological analysis}

Susceptibility to syneresis (STS) and water holding capacity (WHC) was evaluated according to Isanga and Zhang (2009). The substrate (10\% reconstituted skim milk in $0.03 \%$ $\mathrm{CaCl}_{2}, 0.03 \% \mathrm{GDL}$ ), and $1,2,3,4$ and $5 \%$ of the crude enzyme extract were added. The substrate was subsequently incubated at $65^{\circ} \mathrm{C}$ and the formation of curd was observed. The 
coagulation end point was recorded when discrete particles were discernible. The experiment was carried out in triplicate.

\section{Water holding capacity}

The water holding capacity (WHC) was determined according to the following formula:

$$
\mathrm{WHC}(\%)=\left(1-\frac{\mathrm{W}_{1}}{\mathrm{~W}_{2}}\right) \times 100
$$

Where:

$\mathrm{W}_{1}=$ Weight of whey after centrifugation.

$\mathrm{W}_{2}=$ Initial sample weight.

Coagulated milk was centrifuged for $30 \mathrm{~min}$ at $1000 \mathrm{rpm}$ at $4^{\circ} \mathrm{C}$.

\section{Susceptibility to syneresis}

The sample of coagulated milk susceptibility to syneresis (STS) was measured by placing a $100 \mathrm{ml}$ of the sample on a filter paper placed on the top of a funnel. After $6 \mathrm{hr}$., of drainage, the volume of the whey was collected and measured. The index of syneresis is calculated as follows:

Where:

$$
\operatorname{STS}(\%)=\frac{\mathrm{V}_{1}}{\mathrm{~V}_{2}} \times 100
$$

$\mathrm{V}_{1}=$ Volume whey after drainage.

$\mathrm{V}_{2}=$ Initial volume sample.

\section{Statistical Analysis}

The data were analyzed by ANOVA according to the appropriate experimental designs and reported as means ( \pm standard deviations), which were separated by Duncan's Multiple Range Test at $\mathrm{p} \leq 0.05$ (Cochran and Cox, 1992) and least significant difference (LSD) test using SPSS computer program, version 20 (SPSS Inc., Chicago, IL, USA). Triplicate measurements were performed for each analysis.

\section{RESULTS AND DISCUSSION}

\section{Extraction Conditions}

\section{Effect of pH on clotting activity}

Results presented in Table 1 show the effect of different $\mathrm{pH}$ values at $65^{\circ} \mathrm{C}$ on the clotting activity of crude enzyme extracts from artichoke
(Cynara scolymus). Results indicated that reducing $\mathrm{pH}$ value resulted in a great reduction of milk clotting time. Results indicated also that the optimum $\mathrm{pH}$ value was found to be 5.5 to 5 which resulted in short clotting time. These results are in agreement with those reported by Nouani et al. (2009). However, Sidrach et al. (2005) reported that the optimum $\mathrm{pH}$ for artichoke proteases was 5.0, while Chen et al. (2003) found the optimum $\mathrm{pH}$ value was as much as 6.0 for artichoke protease.

Significant decrease in the activity (by about $80-90 \%)$ in $\mathrm{pH}$ value close to the neutrality for the protease of Cynara cardunculus was observed by (Heimgartner et al., 1990; Chazarra et al., 2007).

Nouani et al. (2009) reported that the fig tree and artichoke extracts were stable at the $\mathrm{pH}$ range from $3-7$ and $70-100 \%$ of the initial activity was preserved after $24 \mathrm{hr}$., of incubation at $4^{\circ} \mathrm{C}$ and beyond this $\mathrm{pH}$, the loss of activity was begun, fast for the fig tree extract and slow for the artichoke extract. Similar results are reported by Sidrach et al. (2005) after 60 hr., of incubation at laboratory temperature.

\section{Clotting temperature}

Table 2 shows the effect of temperature on clotting time (sec.) of artichoke proteinase. Results indicated that clotting time was decreased as the clotting temperature raised from $50-70^{\circ} \mathrm{C}$. Moreover, the best clotting activity was noticed at $65-70^{\circ} \mathrm{C}$ which resulted in shorter clotting time. These results are in concordance with those reported by Sidrach et al. (2005) and Nouani et al. (2009).

The thermophilic nature of plant proteases was reported by Sidrach et al. (2005) and Chazarra et al. (2007) on cynarase $\left(70^{\circ} \mathrm{C}\right)$, Raposo and Domingos (2008) on the protease from Centaurea calcitrapa $\left(52^{\circ} \mathrm{C}\right)$, Lo Piero et al. (2002) on the lettucine from Lactuca sativa $\left(50^{\circ} \mathrm{C}\right)$. The study of thermal stability indicated that all the enzymes studied are sensitive to high temperatures. They lose their activity depending on incubation time and the temperature of the reaction medium. At $45^{\circ} \mathrm{C}$, the loss of activity is very rapid during $8 \mathrm{hr}$., of incubation. It is about for rennet and ficine and 30\% for cynarase. At $55^{\circ} \mathrm{C}$, they are totally inactive. The 
Table 1. Effect of pH on milk clotting activity using artichoke crude extracts

\begin{tabular}{|c|c|c|c|c|c|}
\hline \multirow[t]{2}{*}{ Treatment } & \multicolumn{4}{|c|}{ pH values } & \multirow[t]{2}{*}{ Mean effect } \\
\hline & 6.5 & 6.0 & 5.5 & 5.0 & \\
\hline \multicolumn{6}{|c|}{ Clotting time (Sec.) } \\
\hline $\mathbf{T 1}$ & $2286.6^{\mathrm{b}}$ & $271.80^{\mathrm{r}}$ & $190.20^{\mathrm{u}}$ & $133.80^{\mathrm{yz}}$ & $720.6 \pm 838^{\mathrm{a}}$ \\
\hline $\mathbf{T} 2$ & $2190.6^{c}$ & $307.20^{\mathrm{q}}$ & $134.40^{y z}$ & $85.80^{\mathrm{z}}$ & $679.5 \pm 811^{c}$ \\
\hline T3 & $1153.2^{\mathrm{h}}$ & $187.20^{\mathrm{v}}$ & $144.00^{\mathrm{w}}$ & $70.20^{\mathrm{z}}$ & $388.65 \pm 428^{f}$ \\
\hline T4 & $1268.4^{\mathrm{g}}$ & $139.80^{\mathrm{x}}$ & $88.80^{\mathrm{C}}$ & $27.60^{\mathrm{z}}$ & $381.15 \pm 480^{g}$ \\
\hline T5 & $1292.4^{\mathrm{f}}$ & $255.00^{\mathrm{s}}$ & $132.60^{\mathrm{z}}$ & $61.80^{\mathrm{z}}$ & $435.45 \pm 463^{f}$ \\
\hline T6 & $1578.0^{\mathrm{e}}$ & $321.60^{\mathrm{p}}$ & $138.60^{x}$ & $66.60^{\mathrm{z}}$ & $526.2 \pm 569^{\mathrm{e}}$ \\
\hline $\mathbf{T 7}$ & $1874.4^{\mathrm{d}}$ & $324.00^{\circ}$ & $135.60^{y}$ & $69.00^{\mathrm{z}}$ & $600.75 \pm 686^{\mathrm{d}}$ \\
\hline T8 & $2347.2^{\mathrm{a}}$ & $215.40^{t}$ & $126.60^{\mathrm{z}}$ & $93.00^{\mathrm{z}}$ & $695.55 \pm 883^{b}$ \\
\hline \multirow[t]{2}{*}{ Mean effect } & $1748.85 \pm 47^{\mathrm{A}}$ & $252.75 \pm 64^{\mathrm{C}}$ & $136.35 \pm 26^{\mathrm{D}}$ & $75.98 \pm 29^{\mathrm{E}}$ & 553.48 \\
\hline & \multicolumn{5}{|c|}{ U/ml (unit of milk-clotting activity) } \\
\hline T1 & $10.50^{\mathrm{y}}$ & $88.30^{\mathrm{q}}$ & $126.18^{\mathrm{n}}$ & $179.37^{\mathrm{j}}$ & $101.09 \pm 64.0^{\mathrm{g}}$ \\
\hline T2 & $10.96^{\mathrm{y}}$ & $78.13^{r}$ & $178.57^{\mathrm{jk}}$ & $279.72^{f}$ & $136.85 \pm 102^{f}$ \\
\hline T3 & $20.81^{\mathrm{w}}$ & $128.21^{\mathrm{n}}$ & $166.67^{\mathrm{m}}$ & $341.88^{\mathrm{e}}$ & $164.39 \pm 119^{c}$ \\
\hline T4 & $18.92^{\mathrm{wx}}$ & $171.67^{\mathrm{lm}}$ & $270.27^{\mathrm{g}}$ & $869.57^{\mathrm{a}}$ & $332.61 \pm 321^{\mathrm{a}}$ \\
\hline T5 & $18.57^{\mathrm{wx}}$ & $94.12^{\mathrm{q}}$ & $181.00^{\mathrm{j}}$ & $388.35^{\mathrm{b}}$ & $170.51 \pm 137^{\mathrm{b}}$ \\
\hline T6 & $15.21^{\mathrm{xy}}$ & $74.63^{r}$ & $173.16^{\mathrm{kl}}$ & $360.36^{\mathrm{c}}$ & $155.84 \pm 130^{\mathrm{d}}$ \\
\hline T7 & $12.80^{\mathrm{y}}$ & $74.07^{\mathrm{r}}$ & $176.99^{\mathrm{jk}}$ & $347.83^{\mathrm{d}}$ & $152.92 \pm 125^{\mathrm{d}}$ \\
\hline T8 & $10.22^{y}$ & $111.42^{\circ}$ & $189.57^{\mathrm{i}}$ & $258.06^{\mathrm{h}}$ & $142.32 \pm 96.0^{\mathrm{e}}$ \\
\hline Mean effect & $14.75 \pm 4.09^{\mathrm{E}}$ & $102.57 \pm 32.27^{\mathrm{C}}$ & $182.80 \pm 38.41^{\mathrm{B}}$ & $378.14 \pm 200.45^{\mathrm{A}}$ & 169.57 \\
\hline \multicolumn{6}{|c|}{ RA\% (Relative activity) } \\
\hline T1 & $56.52^{\operatorname{lmn}}$ & $93.82^{\mathrm{efg}}$ & $69.72^{\mathrm{hij}}$ & $46.19^{\mathrm{n}}$ & $66.56 \pm 16.61^{\mathrm{d}}$ \\
\hline T2 & $59.00^{\mathrm{klm}}$ & $83.01^{\text {fgh }}$ & $98.66^{\text {efg }}$ & $72.03^{\text {ghi }}$ & $78.18 \pm 13.63^{\mathrm{cd}}$ \\
\hline T3 & $112.07^{\mathrm{def}}$ & $136.22^{\mathrm{cd}}$ & $92.08^{\text {efg }}$ & $88.03^{\mathrm{efg}}$ & $107.10 \pm 55.87^{\mathrm{b}}$ \\
\hline T4 & $101.89^{\text {defg }}$ & $182.40^{\mathrm{b}}$ & $149.32^{\mathrm{bc}}$ & $223.91^{\mathrm{a}}$ & $164.38 \pm 51.44^{\mathrm{a}}$ \\
\hline T5 & $100.00^{\mathrm{efg}}$ & $100.00^{\mathrm{efg}}$ & $100.00^{\mathrm{efg}}$ & $100.00^{\mathrm{efg}}$ & $100.00 \pm 1.47^{\mathrm{b}}$ \\
\hline T6 & $81.90^{\mathrm{fgh}}$ & $79.29^{\mathrm{fgh}}$ & $95.67^{\mathrm{efg}}$ & $92.79^{\text {efg }}$ & $87.41 \pm 6.94^{\mathrm{bc}}$ \\
\hline $\mathbf{T 7}$ & $68.95^{\mathrm{hij}}$ & $78.70^{\text {fgh }}$ & $97.79^{\mathrm{efg}}$ & $89.57^{\mathrm{efg}}$ & $83.75 \pm 10.69^{\mathrm{bc}}$ \\
\hline T8 & $55.06^{\mathrm{mn}}$ & $118.38^{\text {cde }}$ & $104.74^{\text {defg }}$ & $66.45^{\mathrm{ijk}}$ & $86.16 \pm 24.78^{\mathrm{c}}$ \\
\hline Mean effect & $79.42 \pm 21.88^{\mathrm{B}}$ & $108.98 \pm 52.54^{\mathrm{A}}$ & $101.00 \pm 21.28^{\mathrm{A}}$ & $97.37 \pm 51.60^{\mathrm{A}}$ & 96.69 \\
\hline
\end{tabular}

Mean ( \pm SE). Values with small letters in the same column and values with capital letters in the row having different superscripts differ significantly $(\mathrm{p} \leq 0.05)$.

RA: Relative activity: Was calculated as $100 \%$ at $\mathrm{pH}$ and increase or decrease according to clotting time (sec.).

T1=Distilled water, $\mathrm{T} 2=5 \% \mathrm{NaCl}$ in distilled water, $\mathrm{T} 3=5 \% \mathrm{NaCl}$ in sodium acetate buffer $(\mathrm{pH} 3.8$ ), $\mathrm{T} 4=5 \%$ $\mathrm{NaCl}$ in sodium acetate buffer ( $\mathrm{pH} 5.0$ ), $\mathrm{T} 5=5 \% \mathrm{NaCl}$ in sodium phosphate buffer ( $\mathrm{pH} 5.5$ ), $\mathrm{T} 6=5 \% \mathrm{NaCl}$ in sodium phosphate buffer ( $\mathrm{pH}$ 6.5), $\mathrm{T} 7=5 \% \mathrm{NaCl}$ in sodium phosphate buffer ( $\mathrm{pH} 7$ ), $\mathrm{T} 8=5 \% \mathrm{NaCl}$ in Tris- $\mathrm{HCl}$ buffer (pH 8.0). 
Table 2. Effect of temperature on milk clotting activity using artichoke crude extracts

\begin{tabular}{|c|c|c|c|c|c|c|}
\hline \multirow[t]{2}{*}{ Treatment } & \multicolumn{5}{|c|}{ Temperature } & \multirow[t]{2}{*}{ Mean effect } \\
\hline & $50^{\circ} \mathrm{C}$ & $55^{\circ} \mathrm{C}$ & $60^{\circ} \mathrm{C}$ & $65^{\circ} \mathrm{C}$ & $70^{\circ} \mathrm{C}$ & \\
\hline \multicolumn{7}{|c|}{ Clotting time (Sec.) } \\
\hline T1 & $2231^{\mathrm{a}}$ & $628.80^{\text {fgh }}$ & $1189.80^{\mathrm{b}}$ & $798.00^{\mathrm{de}}$ & $563.40^{\text {hij }}$ & $1082.20 \pm 671^{\mathrm{a}}$ \\
\hline $\mathbf{T 2}$ & $793.2^{\mathrm{de}}$ & $621.60^{\mathrm{fg}} \mathrm{h}$ & $550.80^{\text {hij }}$ & $607.20^{\text {ghi }}$ & $493.20^{\mathrm{jkl}}$ & $613.20 \pm 104^{\text {cd }}$ \\
\hline T3 & $985.2^{c}$ & $870.60^{\mathrm{cd}}$ & $658.80^{\mathrm{efg}}$ & $685.20^{\mathrm{efg}}$ & $378.60^{\mathrm{mn}}$ & $715.68 \pm 214^{\mathrm{b}}$ \\
\hline T4 & $753^{\mathrm{def}}$ & $614.40^{\text {fgh }}$ & $561.00^{\mathrm{hij}}$ & $548.40^{\mathrm{hij}}$ & $271.20^{\text {no }}$ & $549.60 \pm 162^{\text {de }}$ \\
\hline T5 & $753.6^{\mathrm{def}}$ & $573.60^{\mathrm{hij}}$ & $469.80^{\mathrm{lm}}$ & $497.40^{\mathrm{ijk}}$ & $186.60^{\circ}$ & $496.20 \pm 190^{\mathrm{e}}$ \\
\hline T6 & $734.4^{\mathrm{def}}$ & $624.60^{\mathrm{fgh}}$ & $633.00^{\mathrm{fgh}}$ & $606.00^{\text {ghi }}$ & $315.00^{\mathrm{no}}$ & $582.60 \pm 146^{\mathrm{cd}}$ \\
\hline $\mathbf{T 7}$ & $684.6^{\mathrm{efg}}$ & $612.00^{\mathrm{fgh}}$ & $477.00^{\mathrm{klm}}$ & $547.20^{\mathrm{hij}}$ & $196.80^{\circ}$ & $503.52 \pm 173^{\mathrm{e}}$ \\
\hline T8 & $852.6^{\mathrm{cd}}$ & $753.00^{\mathrm{def}}$ & $642.00^{\mathrm{fgh}}$ & $667.20^{\mathrm{efg}}$ & $257.40^{\mathrm{no}}$ & $634.44 \pm 209^{c}$ \\
\hline
\end{tabular}

Mean effect $973.45 \pm 493.37^{\mathrm{A}} 662.33 \pm 191.98^{\mathrm{B}} \quad 647.78 \pm 220.26^{\mathrm{B}} \quad 619.58 \pm 91.57^{\mathrm{B}} \quad 332.78 \pm 130.56^{\mathrm{C}} \quad 647.18$

\begin{tabular}{|c|c|c|c|c|c|c|}
\hline \multirow[b]{2}{*}{ T1 } & \multicolumn{6}{|c|}{ U/ml (unit of milk-clotting activity) } \\
\hline & $10.76^{\mathrm{w}}$ & $38.17^{\mathrm{lm}}$ & $20.17^{\mathrm{v}}$ & $30.08^{\mathrm{s}}$ & $42.60^{\mathrm{jk}}$ & $28.36 \pm 12.07^{g}$ \\
\hline $\mathbf{T} 2$ & $30.26^{\mathrm{rs}}$ & $38.61^{\operatorname{lm}}$ & $43.57^{j}$ & $39.53^{1}$ & $48.66^{\mathrm{hi}}$ & $40.13 \pm 6.31^{\mathrm{e}}$ \\
\hline T3 & $24.36^{y}$ & $27.57^{\mathrm{t}}$ & $36.43^{\text {nop }}$ & $35.03^{p}$ & $63.39^{\mathrm{f}}$ & $37.36 \pm 14.27^{\mathrm{f}}$ \\
\hline T4 & $31.87^{\mathrm{qr}}$ & $39.06^{\mathrm{lm}}$ & $42.78^{\mathrm{jk}}$ & $43.76^{\mathrm{j}}$ & $88.50^{\mathrm{d}}$ & $49.19 \pm 20.81^{\mathrm{C}}$ \\
\hline $\mathbf{T 5}$ & $31.85^{\mathrm{qr}}$ & $41.84^{\mathrm{k}}$ & $51.09^{\mathrm{g}}$ & $48.25^{\mathrm{i}}$ & $128.60^{\mathrm{a}}$ & $60.33 \pm 35.99^{\mathrm{a}}$ \\
\hline T6 & $32.68^{\mathrm{q}}$ & $38.42^{\mathrm{lm}}$ & $37.91^{\mathrm{lmn}}$ & $39.60^{1}$ & $76.19^{\mathrm{e}}$ & $44.96 \pm 16.73^{\mathrm{d}}$ \\
\hline T7 & $35.06^{\mathrm{p}}$ & $39.22^{1}$ & $50.31^{\mathrm{gh}}$ & $43.86^{\mathrm{j}}$ & $122.00^{\mathrm{b}}$ & $58.09 \pm 33.55^{b}$ \\
\hline $\mathbf{T 8}$ & $28.15^{\mathrm{t}}$ & $31.87^{\mathrm{qr}}$ & $37.38^{\mathrm{mno}}$ & $35.97^{\mathrm{op}}$ & $93.24^{c}$ & $45.32 \pm 25.03^{\mathrm{d}}$ \\
\hline Mean effect & $28.12 \pm 7.40^{\mathrm{D}}$ & $36.85 \pm 4.51^{\mathrm{C}}$ & $39.96 \pm 9.35^{\mathrm{B}}$ & $39.51 \pm 5.56^{\mathrm{B}}$ & $82.90 \pm 30.21^{\mathrm{A}}$ & 45.47 \\
\hline \multicolumn{7}{|c|}{ RA\% (Relative activity) } \\
\hline T1 & $33.78^{w}$ & $91.22^{\mathrm{g}}$ & $39.49^{v}$ & $62.33^{\mathrm{s}}$ & $33.12^{w}$ & $51.99 \pm 23.11^{\mathrm{h}}$ \\
\hline T2 & $95.01^{\mathrm{d}}$ & $92.28^{\mathrm{efg}}$ & $85.29^{\mathrm{i}}$ & $81.92^{\mathrm{k}}$ & $37.83^{v}$ & $78.47 \pm 21.59^{\mathrm{e}}$ \\
\hline T3 & $76.49^{1}$ & $65.89^{\mathrm{r}}$ & $71.31^{\mathrm{p}}$ & $72.59 o^{p}$ & $49.29^{\mathrm{u}}$ & $67.11 \pm 9.88^{\mathrm{g}}$ \\
\hline T4 & $100.08^{\mathrm{c}}$ & $93.36^{\text {def }}$ & $83.74^{\mathrm{ij}}$ & $90.7^{\mathrm{g}}$ & $68.81^{\mathrm{q}}$ & $87.34 \pm 11.03^{c}$ \\
\hline T5 & $100.00^{\mathrm{c}}$ & $100.00^{\mathrm{c}}$ & $100.00^{\mathrm{c}}$ & $100.00^{\mathrm{c}}$ & $100.00^{\mathrm{c}}$ & $100.00 \pm 1.53^{\mathrm{a}}$ \\
\hline T6 & $102.61^{\mathrm{b}}$ & $91.83^{\mathrm{fg}}$ & $74.22^{\text {no }}$ & $82.08^{\mathrm{jk}}$ & $59.24^{\mathrm{t}}$ & $82.00 \pm 15.38^{\mathrm{d}}$ \\
\hline T7 & $110.08^{\mathrm{a}}$ & $93.73^{\mathrm{de}}$ & $98.49^{c}$ & $90.9^{\mathrm{g}}$ & $94.82^{d}$ & $97.60 \pm 7.18^{\mathrm{b}}$ \\
\hline T8 & $88.39^{\mathrm{h}}$ & $76.18^{\mathrm{lm}}$ & $73.18^{\text {no }}$ & $74.55^{\mathrm{mn}}$ & $72.49^{\mathrm{op}}$ & $76.96 \pm 6.12^{\mathrm{f}}$ \\
\hline
\end{tabular}

$\begin{array}{lllllll}\text { Mean effect } & 88.31 \pm 23.18^{\mathrm{A}} & 88.06 \pm 10.81^{\mathrm{A}} & 78.22 \pm 18.26^{\mathrm{C}} & 81.88 \pm 11.51^{\mathrm{B}} & 64.45 \pm 23.47^{\mathrm{D}} & 80.18\end{array}$

Mean $( \pm$ SE). Values with small letters in the same column and values with capital letters in the row having different superscripts differ significantly $(\mathrm{p} \leq 0.05)$. RA: Relative activity: Was calculated as $100 \%$ at a temperature and increase or decrease according to clotting time (sec.).

$\mathrm{T} 1=$ Distilled water, $\mathrm{T} 2=5 \% \mathrm{NaCl}$ in distilled water, $\mathrm{T} 3=5 \% \mathrm{NaCl}$ in sodium acetate buffer ( $\mathrm{pH} 3.8$ ), $\mathrm{T} 4=5 \%$ $\mathrm{NaCl}$ in sodium acetate buffer ( $\mathrm{pH} 5.0$ ), $\mathrm{T} 5=5 \% \mathrm{NaCl}$ in sodium phosphate buffer ( $\mathrm{pH} 5.5$ ), T6 $=5 \% \mathrm{NaCl}$ in sodium phosphate buffer (pH 6.5), $\mathrm{T} 7=5 \% \mathrm{NaCl}$ in sodium phosphate buffer ( $\mathrm{pH} 7$ ), $\mathrm{T} 8=5 \% \mathrm{NaCl}$ in Tris-HCl buffer (pH 8.0). 
thermostability seems to express a varietal nature. On the other hand, the Centaurea calcitrapa protease retains $100 \%$ of its initial activity at $70^{\circ} \mathrm{C}$ after $6 \mathrm{hr}$., of incubation (Raposo and Domingos, 2008).

Huang et al. (2011) showed that ginger protease had an optimum proteolytic activity at a temperature ranged from 40 to $60^{\circ} \mathrm{C}$ with maximum activity detected at $70^{\circ} \mathrm{C}$. Moreover, $70 \%$ of milk clotting activity was maintained as the temperature was increased to $65^{\circ} \mathrm{C}$ with high specificity for $\kappa$-casein with temperature increasing.

\section{The concentration of crude enzyme extract}

The general rule stating that the time of coagulation ( $\mathrm{T}$ ) in inversely proportion to the amount of the enzyme (E) as expressed by equation $(\mathrm{E} . \times \mathrm{T} .=\mathrm{K})$ holds only true over a narrow range of the enzyme concentration from 1 to $5 / 10 \mathrm{ml}$ of substrate. The results in Table 3 show that the equation $(\mathrm{E} . \times \mathrm{T} .=\mathrm{K})$ is only theoretical, but on the practice, it was found that $(\mathrm{K})$ is nearly constant in crude enzyme extracts of artichoke (Cynara scolymus) from 1 to 5 (ml/ 10 $\mathrm{ml}$ of milk). The results also indicated that the crude enzyme extracts of artichoke were more significantly influenced by enzyme concentration. Results indicated that increasing the extract concentration resulted in decreasing the clotting time. Best clotting activity and acceptable curd properties were obtained at an extract concentration of 3-5\%. It could be also noticed that increasing the enzyme concentration significantly reduced the clotting time (ElAbbassy, 1977; Magdoub et al., 1984 ; Abd ElGelil and El- Zawahary, 2004). These results are in agreement with data reported by Ahmed et al. (2009).

\section{Addition of $\mathrm{CaCl}_{2}$}

The effect of adding $\mathrm{CaCl}_{2}$ at the different concentrations on clotting activity of artichoke protease is shown in Table 4. Results indicated that addition of $\mathrm{CaCl}_{2}$ greatly enhanced the clotting activity of crude enzyme extracts of artichoke and increasing the concentration of $\mathrm{CaCl}_{2}$ greatly reduced the clotting time. The optimum concentration was found to be 0.03$0.05 \%$, which resulted in short clotting time. Nouani et al. (2009) investigated that during the time of the $\mathrm{CaCl}_{2}$ concentration of milk is used in cheese-making $(0-20 \mathrm{mM}$, the per cent composition by mass of the $\mathrm{CaCl}_{2}$ solution is $0.22 \%$ ) the coagulant activity increases progressively (parabolic velocity) depending on $\mathrm{CaC1}_{2}$ concentration. It is fast for commercial rennet (85-90\%) and slows for plant extracts (from $50-80 \%$ ), for the fig tree sap coagulase and from $12-50 \%$ for the coagulase from artichoke flowers. The coagulation of milk by the enzymes planned is slow at concentrations $<10 \mathrm{mM}$ of $\mathrm{CaCl}_{2}\left(10 \mathrm{mM} \mathrm{CaCl}{ }_{2}\right.$ solution is $0.11 \%)$. The artichoke enzyme is the most sensitive. The effect of $\mathrm{Ca}^{++}$ions in the action of enzymatic coagulation of milk (Bencini, 2002; Najera et al., 2003). Lagaude et al. (2004), Chazarra et al. (2007) and Lo Piero et al. (2002), reported that the addition of $\mathrm{CaCl}_{2}$ does not affect catylatic activity of lettucine on whole casein.

\section{Addition of NaCl}

Results presented in Table 5 show the effect of $\mathrm{NaCl}$ addition at different levels on clotting activity of artichoke protease. Results indicated that increasing the level of $\mathrm{NaCl}$ greatly reduced the clotting activity of the different crude extracts of artichoke, showing longer clotting time. Meanwhile, the addition of $\mathrm{NaCl}$ at the level of 3\% could be recommended. Fuquay et al. (2011) reported that the salt or ionic strength may affect the rennet coagulation. The presence of $\mathrm{NaCl}$ in the milk may reduce the milk $\mathrm{pH}$, so its $\mathrm{pH}$ has to be constant during its coagulation because many changes are $\mathrm{pH}$ depending. The addition of $\mathrm{NaCl}\left(>0.01 \mathrm{~mol} \mathrm{l}^{-1} \mathrm{NaCl}\right.$ solution is $5 \times 10^{-4} \%$ ) reduces the hydrolysis reaction, presumably by inhibiting the electrostatic interactions involved in the formation of the chymosin- $\kappa$-casein complex at the active site. And may increases the rennet coagulation time (RCT) throughout reducing the initial rate of aggregation even the $\mathrm{pH}$ value maintained constant. So, if high levels of rennet were used to obtain similar RCT, the adding of $\mathrm{NaCl}$ more than 100-200 mmol ${ }^{-1} \mathrm{NaCl}\left(100-200 \mathrm{mmol} \mathrm{l}^{-1}\right.$ $\mathrm{NaCl}$ solution is $0.58-1.16 \% \mathrm{NaCl}$ ) at a constant milk $\mathrm{pH}$ produces rennet gels with the high storage module. These results highlight the important role of electrostatic interactions in the rennet coagulation step. Besides to that, adding of $\mathrm{NaCl}$ may result in some solubilization of colloidal calcium phosphate (CCP) as well and it may due to substitution/exchange of $\mathrm{Na}^{+}$for $\mathrm{Ca}^{2+}$. 
Abdel-Raouf, et al.

Table 3. Effect of enzyme concentration on milk clotting activity using artichoke crude extracts

\begin{tabular}{|c|c|c|c|c|c|c|}
\hline \multirow[t]{2}{*}{ Treatment } & \multicolumn{5}{|c|}{ Concentration of crude extract } & \multirow[t]{2}{*}{ Mean effect } \\
\hline & $1 \%$ & $2 \%$ & $3 \%$ & $4 \%$ & $5 \%$ & \\
\hline & \multicolumn{6}{|c|}{ Clotting time (Sec.) } \\
\hline $\mathbf{T 1}$ & $846.6^{\mathrm{a}}$ & $553.2^{\mathrm{h}}$ & $377.4^{\mathrm{m}}$ & $262.2^{t}$ & $75.0^{\mathrm{E}}$ & $422 \pm 272^{\mathrm{a}}$ \\
\hline $\mathbf{T} 2$ & $672.6^{\mathrm{e}}$ & $367.2^{\circ}$ & $253.2^{\mathrm{v}}$ & $198.6^{\mathrm{A}}$ & $66.6^{\mathrm{F}}$ & $311 \pm 211^{\mathrm{e}}$ \\
\hline T3 & $739.2^{\mathrm{b}}$ & $439.2^{\mathrm{j}}$ & $313.2^{\mathrm{q}}$ & $208.2^{x}$ & $60.0^{\mathrm{G}}$ & $351 \pm 238^{b}$ \\
\hline T4 & $621.6^{\mathrm{f}}$ & $373.8^{\mathrm{n}}$ & $271.2^{r}$ & $153^{\mathrm{B}}$ & $33.0^{\mathrm{I}}$ & $290 \pm 208^{f}$ \\
\hline $\mathbf{T 5}$ & $549.0^{\mathrm{i}}$ & $373.2^{\mathrm{n}}$ & $269.4^{\mathrm{s}}$ & $147^{\mathrm{D}}$ & $30.6^{\mathrm{J}}$ & $273 \pm 18^{g} 5$ \\
\hline T6 & $681.6^{\mathrm{d}}$ & $421.8^{l}$ & $252.6^{\mathrm{v}}$ & $199.8^{z}$ & $34.8^{\mathrm{H}}$ & $318 \pm 227^{\mathrm{d}}$ \\
\hline T7 & $607.8^{\mathrm{g}}$ & $318.0^{p}$ & $250.8^{\mathrm{w}}$ & $150.6^{\mathrm{C}}$ & $32.4^{\mathrm{I}}$ & $271 \pm 200^{\mathrm{h}}$ \\
\hline T8 & $738.0^{c}$ & $427.8^{k}$ & $257.4^{\mathrm{u}}$ & $202.8^{y}$ & $33.0^{I}$ & $331 \pm 247^{\mathrm{c}}$ \\
\hline \multirow[t]{2}{*}{ Mean effect } & $682.05 \pm 88^{\mathrm{A}}$ & $409.28 \pm 67^{\mathrm{B}}$ & $280.65 \pm 42^{\mathrm{C}}$ & $190.28 \pm 37^{\mathrm{D}}$ & $45.68 \pm 17^{\mathrm{E}}$ & 321.58 \\
\hline & \multicolumn{6}{|c|}{ E. $\times$ T. $=K$} \\
\hline T1 & $846.6^{\mathrm{p}}$ & $1659.6^{\mathrm{c}}$ & $1887.0^{\mathrm{a}}$ & $1835.4^{b}$ & $675.0^{r}$ & $1380.72 \pm 533^{a}$ \\
\hline $\mathbf{T 2}$ & $672.6^{\mathrm{r}}$ & $1101.6^{\mathrm{l}}$ & $1266.0^{\mathrm{jk}}$ & $1390.2^{\mathrm{g}}$ & $599.4^{\mathrm{s}}$ & $1005.96 \pm 327^{c}$ \\
\hline T3 & $739.2^{q}$ & $1317.0^{\mathrm{i}}$ & $1566.0^{\mathrm{d}}$ & $1457.4^{\mathrm{e}}$ & $540.0^{\mathrm{t}}$ & $1124.04 \pm 4.24^{b}$ \\
\hline T4 & $621.6^{\mathrm{s}}$ & $1121.4^{1}$ & $1356.0^{\mathrm{h}}$ & $1071.0^{\mathrm{m}}$ & $297.0^{\mathrm{uv}}$ & $893.40 \pm 394^{e}$ \\
\hline T5 & $549.0^{\mathrm{t}}$ & $1119.6^{l}$ & $1347.0^{\mathrm{h}}$ & $1029.0^{\mathrm{n}}$ & $275.4^{\mathrm{v}}$ & $864.00 \pm 406^{f}$ \\
\hline T6 & $681.6^{\mathrm{r}}$ & $1265.4^{\mathrm{jk}}$ & $1263.0^{\mathrm{jk}}$ & $1398.6^{\mathrm{fg}}$ & $313.2^{\mathrm{u}}$ & $984.36 \pm 431^{\mathrm{d}}$ \\
\hline T7 & $607.8^{\mathrm{s}}$ & $954.0^{\circ}$ & $1254.0^{\mathrm{k}}$ & $1054.2^{\mathrm{mn}}$ & $291.6^{\mathrm{uv}}$ & $832.32 \pm 353^{g}$ \\
\hline T8 & $738.0^{\mathrm{q}}$ & $1283.4^{j}$ & $1287.0^{\mathrm{j}}$ & $1419.6^{\mathrm{f}}$ & $297.0^{\mathrm{uv}}$ & $1005.00 \pm 439^{\mathrm{C}}$ \\
\hline \multirow[t]{2}{*}{ Mean effect } & $682.05 \pm 88.79^{\mathrm{D}}$ & $1227.83 \pm 204^{\mathrm{C}}$ & $1403.25 \pm 210^{\mathrm{A}}$ & $1331.93 \pm 261^{\mathrm{B}}$ & $411.08 \pm 157.46^{\mathrm{E}}$ & 1011.23 \\
\hline & \multicolumn{6}{|c|}{$1 / \mathrm{t} \times 10^{3}$} \\
\hline T1 & $1.18^{\mathrm{u}}$ & $1.81 .0^{\mathrm{r}}$ & $2.65^{p}$ & $3.81^{\operatorname{lmn}}$ & $13.33^{\mathrm{g}}$ & $4.56 \pm 4.63^{\mathrm{g}}$ \\
\hline $\mathbf{T 2}$ & $1.49^{\mathrm{st}}$ & $2.72 .0^{\mathrm{p}}$ & $3.95^{1}$ & $5.04^{\mathrm{j}}$ & $15.02^{f}$ & $5.64 \pm 5.07^{\mathrm{f}}$ \\
\hline T3 & $1.35^{\mathrm{tu}}$ & $2.28 .0^{\mathrm{q}}$ & $3.19^{\circ}$ & $4.80^{\mathrm{k}}$ & $16.67^{\mathrm{e}}$ & $5.66 \pm 5.81^{\mathrm{f}}$ \\
\hline T4 & $1.61^{\mathrm{s}}$ & $2.68 .0^{\mathrm{p}}$ & $3.69^{n}$ & $6.54^{\mathrm{i}}$ & $30.30^{c}$ & $8.96 \pm 11.17^{\mathrm{C}}$ \\
\hline T5 & $1.82^{\mathrm{r}}$ & $2.68 .0^{\mathrm{p}}$ & $3.71^{\mathrm{mn}}$ & $6.80^{\mathrm{h}}$ & $32.68^{\mathrm{a}}$ & $9.54 \pm 12.10^{\mathrm{a}}$ \\
\hline T6 & $1.47^{\text {st }}$ & $2.37 .0^{q}$ & $3.96^{\mathrm{l}}$ & $5.01^{\mathrm{j}}$ & $28.74^{d}$ & $8.31 \pm 10.65^{\mathrm{e}}$ \\
\hline T7 & $1.65^{\mathrm{rs}}$ & $3.14 .0^{\circ}$ & $3.99^{\mathrm{l}}$ & $6.64^{\text {hi }}$ & $30.86^{\mathrm{b}}$ & $9.26 \pm 11.30^{\mathrm{b}}$ \\
\hline T8 & $1.36^{\mathrm{tu}}$ & $2.34 .0^{\mathrm{q}}$ & $3.89^{\operatorname{lm}}$ & $4.93^{\mathrm{jk}}$ & $30.30^{c}$ & $8.56 \pm 11.32^{d}$ \\
\hline Mean effect & $1.49 \pm 0.20^{\mathrm{E}}$ & $2.50 \pm 0.39^{\mathrm{D}}$ & $3.63 \pm 0.45^{\mathrm{C}}$ & $5.45 \pm 1.03^{\mathrm{B}}$ & $24.74 \pm 7.81^{\mathrm{A}}$ & 7.56 \\
\hline
\end{tabular}

Mean $( \pm \mathrm{SE})$. Values with small letters in the same column and values with capital letters in the row having different superscripts differ significantly $(\mathrm{p} \leq 0.05)$.

E.: enzyme concentration

$\mathrm{T} 1=$ Distilled water, $\mathrm{T} 2=5 \% \mathrm{NaCl}$ in distilled water, $\mathrm{T} 3=5 \% \mathrm{NaCl}$ in sodium acetate buffer $(\mathrm{pH} 3.8)$, $\mathrm{T} 4=5 \%$ $\mathrm{NaCl}$ in sodium acetate buffer ( $\mathrm{pH} 5.0$ ), $\mathrm{T} 5=5 \% \mathrm{NaCl}$ in sodium phosphate buffer ( $\mathrm{pH} 5.5$ ), $\mathrm{T} 6=5 \% \mathrm{NaCl}$ in sodium phosphate buffer ( $\mathrm{pH}$ 6.5), $\mathrm{T} 7=5 \% \mathrm{NaCl}$ in sodium phosphate buffer ( $\mathrm{pH} 7), \mathrm{T} 8=5 \% \mathrm{NaCl}$ in Tris- $\mathrm{HCl}$ buffer (pH 8.0). 
Zagazig J. Agric. Res., Vol. 44 No. (6A) 2017

Table 4. Effect of $\mathrm{CaCl}_{2}$ concentration on milk clotting activity using artichoke crude extracts

\begin{tabular}{|c|c|c|c|c|c|c|c|}
\hline \multirow[t]{2}{*}{$\overline{\text { Treatment }}$} & \multicolumn{6}{|c|}{$\mathrm{CaCl}_{2}$ concentration } & \multirow[t]{2}{*}{ Mean effect } \\
\hline & $0.0 \%$ & $0.01 \%$ & $0.02 \%$ & $0.03 \%$ & $0.04 \%$ & $0.05 \%$ & \\
\hline \multicolumn{8}{|c|}{ Clotting time (Sec.) } \\
\hline $\mathbf{T 1}$ & $1273.8^{\mathrm{a}}$ & $1024.2^{\mathrm{g}}$ & $669.6^{p}$ & $456.6^{\mathrm{u}}$ & $317.4^{\mathrm{z}}$ & $150.6^{\mathrm{z}}$ & $648.70 \pm 404^{\mathrm{a}}$ \\
\hline $\mathbf{T} 2$ & $1092.6^{\mathrm{d}}$ & $813.6^{\mathrm{m}}$ & $444.6^{w}$ & $306.6^{\mathrm{D}}$ & $240.6^{\mathrm{z}}$ & $140.4^{\mathrm{z}}$ & $506.40 \pm 348^{\mathrm{d}}$ \\
\hline T3 & $1164.6^{b}$ & $894.6^{\mathrm{j}}$ & $531.6^{r}$ & $379.2^{\mathrm{y}}$ & $252.0^{\mathrm{z}}$ & $132.6^{\mathrm{z}}$ & $559.10 \pm 373^{b}$ \\
\hline T4 & $972.6^{\mathrm{h}}$ & $752.4^{n}$ & $452.4^{\mathrm{v}}$ & $328.2^{\mathrm{z}}$ & $185.4^{\mathrm{z}}$ & $82.2^{\mathrm{z}}$ & $462.20 \pm 320^{\mathrm{f}}$ \\
\hline T5 & $932.4^{\mathrm{i}}$ & $664.2^{\mathrm{q}}$ & $451.8^{v}$ & $325.8^{\mathrm{z}}$ & $177.6^{\mathrm{z}}$ & $73.2^{\mathrm{z}}$ & $437.50 \pm 299^{h}$ \\
\hline T6 & $1027.2^{f}$ & $825.0^{l}$ & $510.6^{\mathrm{t}}$ & $305.4^{\mathrm{z}}$ & $241.8^{\mathrm{z}}$ & $94.2^{\mathrm{z}}$ & $500.70 \pm 339^{\mathrm{e}}$ \\
\hline T7 & $1041.0^{\mathrm{e}}$ & $735.6^{\circ}$ & $384.6^{\mathrm{x}}$ & $303.6^{\mathrm{z}}$ & $182.4^{\mathrm{z}}$ & $90.6^{\mathrm{z}}$ & $456.30 \pm 340^{\mathrm{g}}$ \\
\hline T8 & $1112.4^{c}$ & $892.8^{\mathrm{k}}$ & $517.8^{\mathrm{s}}$ & $311.4^{\mathrm{z}}$ & $245.4^{\mathrm{z}}$ & $142.2^{\mathrm{z}}$ & $537.00 \pm 363^{\mathrm{c}}$ \\
\hline Mean effect & $1077.08 \pm 104^{\mathrm{A}}$ & $825.30 \pm 107^{\mathrm{B}}$ & $495.38 \pm 81^{C}$ & $339.60 \pm 50^{\mathrm{D}}$ & $230.33 \pm 45^{\mathrm{E}}$ & $113.25 \pm 29^{\mathrm{F}}$ & 513.49 \\
\hline \multicolumn{8}{|c|}{ U/ml (unit of milk-clotting activity) } \\
\hline T1 & $18.84^{\mathrm{z}}$ & $23.43^{\mathrm{BC}}$ & $35.84^{\mathrm{w}}$ & $52.56^{\mathrm{t}}$ & $75.61^{q}$ & $159.36^{\mathrm{h}}$ & $60.94 \pm 49^{\mathrm{h}}$ \\
\hline $\mathbf{T 2}$ & $21.97^{\mathrm{z}}$ & $29.5^{y}$ & $53.98^{t}$ & $78.28^{\mathrm{op}}$ & $99.75^{1}$ & $170.94^{\mathrm{f}}$ & $75.74 \pm 51^{\mathrm{e}}$ \\
\hline T3 & $20.61^{z}$ & $26.83^{z}$ & $45.15^{\mathrm{v}}$ & $63.29^{\mathrm{s}}$ & $95.24^{\mathrm{n}}$ & $181.00^{\mathrm{e}}$ & $72.02 \pm 56^{\mathrm{g}}$ \\
\hline T4 & $24.68^{\mathrm{z}}$ & $31.9 .0^{\mathrm{x}}$ & $53.05^{\mathrm{t}}$ & $73.13^{r}$ & $129.45^{\mathrm{k}}$ & $291.97^{\mathrm{b}}$ & $100.70 \pm 94^{\mathrm{b}}$ \\
\hline T5 & $25.74^{\mathrm{z}}$ & $36.13^{\mathrm{w}}$ & $53.12^{t}$ & $73.66^{r}$ & $135.14^{\mathrm{i}}$ & $327.87^{\mathrm{a}}$ & $108.61 \pm 107^{\mathrm{a}}$ \\
\hline T6 & $23.36^{\mathrm{z}}$ & $29.09^{y}$ & $47.00^{\mathrm{u}}$ & $78.59^{\mathrm{op}}$ & $99.26^{\mathrm{lm}}$ & $254.78^{\mathrm{d}}$ & $88.68 \pm 81^{d}$ \\
\hline T7 & $23.05^{\mathrm{z}}$ & $32.63^{x}$ & $62.40^{\mathrm{s}}$ & $79.05^{\circ}$ & $131.58^{j}$ & $264.90^{c}$ & $98.94 \pm 84^{c}$ \\
\hline T8 & $21.57^{\mathrm{z}}$ & $26.88^{z}$ & $46.35^{\mathrm{uv}}$ & $77.07^{\mathrm{pq}}$ & $97.80^{\mathrm{m}}$ & $168.78^{\mathrm{g}}$ & $73.08 \pm 51^{f}$ \\
\hline Mean effect & $22.48 \pm 2^{\mathrm{F}}$ & $29.55 \pm 3^{E}$ & $49.61 \pm 7^{\mathrm{D}}$ & $71.95 \pm 8^{\mathrm{C}}$ & $107.98 \pm 8^{\mathrm{B}}$ & $227.45 \pm 62^{\mathrm{A}}$ & 84.33 \\
\hline \multicolumn{8}{|c|}{ RA\% (Relative activity) } \\
\hline T1 & $100.00^{\mathrm{s}}$ & $124.37^{N}$ & $190.23^{F}$ & $278.98^{A}$ & $401.32^{\mathrm{t}}$ & $845.82^{h}$ & $323.45 \pm 361^{\mathrm{h}}$ \\
\hline $\mathbf{T 2}$ & $116.58^{P}$ & $156.56^{\mathrm{I}}$ & $286.50^{y}$ & $415.46^{r}$ & $529.43^{1}$ & $907.26^{f}$ & $401.97 \pm 274^{\mathrm{e}}$ \\
\hline T3 & $109.38^{\mathrm{R}}$ & $142.39^{\mathrm{K}}$ & $239.62^{\mathrm{D}}$ & $335.92^{w}$ & $505.48^{\circ}$ & $960.63^{\mathrm{e}}$ & $382.24 \pm 298^{g}$ \\
\hline T4 & $130.97^{\mathrm{M}}$ & $169.30^{\mathrm{H}}$ & $281.56^{\mathrm{z}}$ & $388.12^{v}$ & $687.06^{\mathrm{k}}$ & $1549.64^{\mathrm{b}}$ & $534.44 \pm 503^{b}$ \\
\hline T5 & $136.62^{\mathrm{L}}$ & $191.78^{\mathrm{E}}$ & $281.94^{\mathrm{z}}$ & $390.98^{\mathrm{u}}$ & $717.23^{\mathrm{i}}$ & $1740.16^{\mathrm{a}}$ & $576.45 \pm 569^{\mathrm{a}}$ \\
\hline T6 & $124.01^{\mathrm{N}}$ & $154.40^{\mathrm{J}}$ & $249.47^{\text {B }}$ & $417.09^{q}$ & $526.80^{\mathrm{m}}$ & $1352.23^{\mathrm{d}}$ & $470.67 \pm 430^{d}$ \\
\hline T7 & $122.36^{\mathrm{O}}$ & $173.16^{G}$ & $331.20^{x}$ & $419.57^{\mathrm{P}}$ & $698.36^{j}$ & $1405.96^{\mathrm{c}}$ & $525.10 \pm 448^{\mathrm{C}}$ \\
\hline T8 & $114.51^{\mathrm{Q}}$ & $142.67^{\mathrm{K}}$ & $246.00^{\mathrm{C}}$ & $409.06^{\mathrm{s}}$ & $519.07^{n}$ & $895.78^{g}$ & $387.85 \pm 275^{\mathrm{f}}$ \\
\hline Mean effect & $119.30 \pm 11^{\mathrm{F}}$ & $156.83 \pm 20^{\mathrm{E}}$ & $263.32 \pm 39^{D}$ & $381.90 \pm 47^{\mathrm{C}}$ & $573.09 \pm 108^{\mathrm{B}}$ & $1207.19 \pm 331^{\mathrm{A}}$ & 450.27 \\
\hline
\end{tabular}

Mean $( \pm \mathrm{SE})$. Values with small letters in the same column and values with capital letters in the row having different superscripts differ significantly $(\mathrm{p} \leq 0.05)$.

RA: Relative activity: Was calculated as $100 \%$ at without added $\mathrm{CaCl}_{2}$ and increase or decrease according to clotting time (sec.).

T1=Distilled water, $\mathrm{T} 2=5 \% \mathrm{NaCl}$ in distilled water, $\mathrm{T} 3=5 \% \mathrm{NaCl}$ in sodium acetate buffer (pH 3.8), T4=5\% $\mathrm{NaCl}$ in sodium acetate buffer $(\mathrm{pH} 5.0), \mathrm{T} 5=5 \% \mathrm{NaCl}$ in sodium phosphate buffer (pH 5.5), $\mathrm{T} 6=5 \% \mathrm{NaCl}$ in sodium phosphate buffer ( $\mathrm{pH}$ 6.5), $\mathrm{T} 7=5 \% \mathrm{NaCl}$ in sodium phosphate buffer ( $\mathrm{pH} 7$ ), $\mathrm{T} 8=5 \% \mathrm{NaCl}$ in Tris- $\mathrm{HCl}$ buffer (pH 8.0). 
Table 5. Effect of $\mathrm{NaCl}$ concentration on milk clotting activity using artichoke crude extracts

\begin{tabular}{|c|c|c|c|c|c|c|c|}
\hline \multirow[t]{2}{*}{ Treatments } & \multicolumn{6}{|c|}{ NaCl concentration } & \multirow[t]{2}{*}{ Mean effect } \\
\hline & $0.0 \%$ & $1 \%$ & $3 \%$ & $5 \%$ & $7 \%$ & $10 \%$ & \\
\hline & \multicolumn{7}{|c|}{ Clotting time (Sec.) } \\
\hline T1 & $1209.0^{\mathrm{lm}}$ & $1034.4^{p}$ & $1753.2^{\mathrm{e}}$ & $2400.0^{\mathrm{a}}$ & $1164.6^{\mathrm{n}}$ & $1620.0^{\mathrm{g}}$ & $1530.20 \pm 478^{\mathrm{b}}$ \\
\hline $\mathbf{T} 2$ & $1026.6^{p}$ & $852.6^{\mathrm{t}}$ & $974.4^{\mathrm{q}}$ & $1091.4^{\circ}$ & $1158.6^{\mathrm{n}}$ & $1620.0^{\mathrm{g}}$ & $1120.60 \pm 249^{f}$ \\
\hline T3 & $1173.0^{\mathrm{mn}}$ & $984.6^{\mathrm{q}}$ & $1467.0^{\mathrm{j}}$ & $2100.0^{b}$ & $2400^{.0 a}$ & $2400.0^{\mathrm{a}}$ & $1754.10 \pm 589^{\mathrm{a}}$ \\
\hline T4 & $930.6^{r}$ & $727.2^{v}$ & $795.0^{\mathrm{u}}$ & $936.0^{r}$ & $1273.8^{k}$ & $1980.0^{\mathrm{c}}$ & $1107.10 \pm 438^{\mathrm{f}}$ \\
\hline T5 & $873.6^{\mathrm{st}}$ & $806.4^{\mathrm{u}}$ & $846.6^{t}$ & $918.0^{r}$ & $1475.4^{\mathrm{ij}}$ & $1509.6^{\mathrm{i}}$ & $1071.60 \pm 308^{g}$ \\
\hline T6 & $979.2^{\mathrm{q}}$ & $858.6^{t}$ & $907.8^{\text {rs }}$ & $1043.4^{p}$ & $1577.4^{h}$ & $1591.2^{\mathrm{gh}}$ & $1159.60 \pm 314^{\mathrm{e}}$ \\
\hline T7 & $987.0^{\mathrm{q}}$ & $924.6^{r}$ & $974.4^{\mathrm{q}}$ & $1054.2^{\text {op }}$ & $1896.0^{\mathrm{d}}$ & $1230.6^{l}$ & $1177.80 \pm 349^{d}$ \\
\hline T8 & $1030.8^{p}$ & $980.4^{\mathrm{q}}$ & $1152.6^{n}$ & $1269.0^{\mathrm{k}}$ & $1686.0^{f}$ & $1053.6^{\text {op }}$ & $1195.40 \pm 245^{\mathrm{c}}$ \\
\hline \multirow[t]{2}{*}{ Mean effect } & $1026.23 \pm 119^{\mathrm{E}}$ & $896.10 \pm 98.74^{\mathrm{F}}$ & $1108.88 \pm 320^{\mathrm{D}}$ & $1351.50 \pm 545^{C}$ & $1578.98 \pm 401^{\mathrm{B}}$ & $1625.63 \pm 399^{\mathrm{A}}$ & 1264.55 \\
\hline & \multicolumn{7}{|c|}{ U/ml (unit of milk-clotting activity) } \\
\hline T1 & $19.85^{r}$ & $23.20^{\text {no }}$ & $821.36^{\mathrm{g}}$ & $10.00^{\mathrm{z}}$ & $20.61^{\mathrm{q}}$ & $14.81^{\mathrm{u}}$ & $151.64 \pm 308^{h}$ \\
\hline $\mathbf{T 2}$ & $23.38^{n}$ & $28.15^{j}$ & $1477.83^{d}$ & $21.99^{p}$ & $20.71^{\mathrm{q}}$ & $14.81^{\mathrm{u}}$ & $264.48 \pm 558^{\mathrm{d}}$ \\
\hline T3 & $20.46^{\mathrm{q}}$ & $24.38^{\mathrm{m}}$ & $981.60^{f}$ & $11.43^{y}$ & $10.00^{\mathrm{z}}$ & $10.00^{\mathrm{z}}$ & $176.31 \pm 370^{g}$ \\
\hline T4 & $25.79^{1}$ & $33.00^{h}$ & $1811.32^{\mathrm{a}}$ & $25.64^{l}$ & $18.84^{\mathrm{s}}$ & $12.12^{\mathrm{x}}$ & $321.12 \pm 685^{\mathrm{a}}$ \\
\hline T5 & $27.47^{\mathrm{k}}$ & $29.76^{\mathrm{i}}$ & $1700.92^{b}$ & $26.14^{l}$ & $16.27^{\mathrm{t}}$ & $15.90^{t}$ & $302.74 \pm 643^{b}$ \\
\hline T6 & $24.51^{\mathrm{m}}$ & $27.95^{\mathrm{jk}}$ & $1586.25^{c}$ & $23.00^{\text {no }}$ & $15.21^{\mathrm{u}}$ & $15.08^{\mathrm{u}}$ & $282.00 \pm 600^{\mathrm{C}}$ \\
\hline T7 & $24.32^{\mathrm{m}}$ & $25.96^{l}$ & $1477.83^{d}$ & $22.77^{\circ}$ & $12.66^{\mathrm{w}}$ & $19.50^{r}$ & $263.84 \pm 558^{\mathrm{e}}$ \\
\hline T8 & $23.28^{\text {no }}$ & $24.48^{\mathrm{m}}$ & $1249.35^{\mathrm{e}}$ & $18.91^{\mathrm{s}}$ & $14.23^{\mathrm{v}}$ & $22.78^{\circ}$ & $225.51 \pm 471^{\mathrm{f}}$ \\
\hline \multirow[t]{2}{*}{ Mean effect } & $23.63 \pm 2.43^{\mathrm{C}}$ & $27.11 \pm 3.12^{\mathrm{B}}$ & $1388.31 \pm 330^{\mathrm{A}}$ & $19.99 \pm 5.88^{\mathrm{D}}$ & $16.07 \pm 3.66^{\mathrm{E}}$ & $15.63 \pm 3.84^{\mathrm{F}}$ & 248.45 \\
\hline & \multicolumn{7}{|c|}{ RA\% (Relative activity) } \\
\hline T1 & $100.00^{\mathrm{m}}$ & $116.88^{\text {hij }}$ & $68.96^{r}$ & $50.38^{v}$ & $103.81^{l}$ & $74.63^{p}$ & $85.78 \pm 23^{g}$ \\
\hline $\mathbf{T} 2$ & $117.77^{\mathrm{h}}$ & $141.8^{c}$ & $124.08^{g}$ & $110.78^{\mathrm{k}}$ & $104.35^{l}$ & $74.63^{p}$ & $112.24 \pm 21^{c}$ \\
\hline T3 & $103.07^{l}$ & $122.79^{g}$ & 82.41 o & $57.57^{\mathrm{u}}$ & $50.38^{v}$ & $50.38^{v}$ & $77.77 \pm 28^{\mathrm{h}}$ \\
\hline T4 & $129.92^{\mathrm{f}}$ & $166.25^{\mathrm{a}}$ & $152.08^{b}$ & $129.17^{\mathrm{f}}$ & $94.91^{n}$ & $61.06^{\mathrm{t}}$ & $122.23 \pm 36^{\mathrm{a}}$ \\
\hline T5 & $138.39^{d}$ & $149.93^{b}$ & $142.81^{\mathrm{c}}$ & $131.7^{\mathrm{ef}}$ & $81.94^{\circ}$ & $80.09^{\circ}$ & $120.81 \pm 29^{b}$ \\
\hline T6 & $123.47^{\mathrm{g}}$ & $140.81 c^{d}$ & $133.18^{\mathrm{e}}$ & $115.87^{\text {hij }}$ & $76.65^{p}$ & $75.98^{p}$ & $110.99 \pm 26^{\mathrm{d}}$ \\
\hline T7 & $122.49^{g}$ & $130.76^{\text {ef }}$ & $124.08^{g}$ & $114.68^{\mathrm{j}}$ & $63.77^{\mathrm{s}}$ & $98.24^{\mathrm{m}}$ & $109.00 \pm 23^{\mathrm{e}}$ \\
\hline T8 & $117.29^{\text {hi }}$ & $123.32^{\mathrm{g}}$ & $104.89^{l}$ & $95.27^{n}$ & $71.71^{\mathrm{q}}$ & $114.75^{\mathrm{ij}}$ & $104.54 \pm 17^{f}$ \\
\hline Mean effect & $119.05 \pm 12^{\mathrm{B}}$ & $136.57 \pm 15^{\mathrm{A}}$ & $116.56 \pm 27^{\mathrm{C}}$ & $100.68 \pm 29^{\mathrm{D}}$ & $80.94 \pm 18^{\mathrm{E}}$ & $78.72 \pm 19^{\mathrm{F}}$ & 105.41 \\
\hline
\end{tabular}

Mean $( \pm$ SE). Values with small letters in the same column and values with capital letters in the row having different superscripts differ significantly $(\mathrm{p} \leq 0.05)$.

RA: Relative activity: Was calculated as $100 \%$ at without added $\mathrm{NaCl}$ and increase or decrease according to clotting time (sec.).

T1=Distilled water, $\mathrm{T} 2=5 \% \mathrm{NaCl}$ in distilled water, $\mathrm{T} 3=5 \% \mathrm{NaCl}$ in sodium acetate buffer $(\mathrm{pH} 3.8$ ), $\mathrm{T} 4=5 \%$ $\mathrm{NaCl}$ in sodium acetate buffer $(\mathrm{pH} 5.0), \mathrm{T} 5=5 \% \mathrm{NaCl}$ in sodium phosphate buffer ( $\mathrm{pH} 5.5$ ), $\mathrm{T} 6=5 \% \mathrm{NaCl}$ in sodium phosphate buffer ( $\mathrm{pH}$ 6.5), $\mathrm{T} 7=5 \% \mathrm{NaCl}$ in sodium phosphate buffer ( $\mathrm{pH} 7), \mathrm{T} 8=5 \% \mathrm{NaCl}$ in $\mathrm{Tris}-\mathrm{HCl}$ buffer (pH 8.0). 
Zhao and Corredig (2016) reported the same observation concerning the presence of $\mathrm{NaCl}$ where its high levels inhibition the gelation and increasing the rennet coagulation time and decreasing the gel stiffness as well compared to control. Also, reported that the final level of $\mathrm{NaCl}$ was about 280 and $260 \mathrm{mmol} / \mathrm{l}$ (280 and $260 \mathrm{mmol} / \mathrm{l}$ solution is $1.5-1.6 \% \mathrm{NaCl}$ ) and the presence of $300 \mathrm{mM} \mathrm{NaCl}(300 \mathrm{mM} \mathrm{NaCl}$ solution is $1.7 \% \mathrm{NaCl}$ ) led to solubilization of CCP and decreasing both the $\mathrm{pH}$ and the negative charges on the surface of casein micelles.

\section{Addition of GDL}

Results presented in Table 6 show that addition of Glucono-Delta-Lactone (GDL) greatly reduced the clotting time of artichoke protease up to $0.30 \%$. However, increasing the level of GDL more than $0.3 \%$ increased again the clotting time. So, it could be noticed that the optimum concentration of GDL was $0.2-0.4 \%$. However, preheating the skimmed milk to $90^{\circ} \mathrm{C}$ followed by acidification at $30^{\circ} \mathrm{C}$ using slows hydrolysis of GDL shifting the coagulation $\mathrm{pH}$ to a value higher than 5.5, and reduces the coagulation time (Horne and Davidson, 1993). These results could be explained on the basis that clotting time of the artichoke was faster with higher acidity and lower $\mathrm{pH}$ value (Esposito et al., 2016).

\section{Proteolytic activity}

The photolytic activity of crude extracts of artichoke in different buffers is shown in Table 7. Results indicated that artichoke extracted in sodium phosphate buffer (T5, T7 and T6) had higher photolytic activity than other buffers. These results are in agreement with those reported by Liorente et al. (2014) as they reported that artichoke protease showed higher photolytic activity at $\mathrm{pH}$ 5.0-6.0 but the highest proteolytic activity was noticed at $\mathrm{pH}$ 5.0.

Nunez et al. (1991) reported that proteolysis of La Serena cheese was found to be at a higher rate when it was made using vegetable rennet than that made using calf rennet. Abd El-Gelil and El-Zawahary (2004) also reported that the enzyme extract from Solanum dobium plant showed strong proteolytic activity than calf rennet. The breaking off of the Phe 105-Met 106 bond from $\kappa$-casein by aspartyl proteases such as cynarase is similar to that of chymosin and the other proteases of fungal and bacterial (Sidrach et al., 2005). Moreover, the proteolytic effect was the same of Cynara cardunculus, which largely used in cheese making (Campos et al., 1990; Silva and Malcata, 1999; Silva et al., 2002). In another comparative study of Heimgartner et al. (1990) and Cordeiro et al. (1992), they showed an excessive proteolytic activity in crude extracts containing cyranase compared to chymosin. This may be due to the non-specific action of the proteases towards the other milk caseins ( $\alpha$ s, and ( $\beta$-caseins). The bovine $\alpha$-, $\beta$ - and $\kappa$-casein can be hydrolyzed by the three types of cynarases (A, B and C) while only $\kappa$-casein can be hydrolyzed by the crude extract from artichoke at the same peptide band similar to the calf rennet. Moreover, the electrophoretic patterns resulted from $\alpha$ and $\beta$ casein were depending on the type of cynarases ( $\mathrm{A}, \mathrm{B}$ and $\mathrm{C}$ ). These patterns were similar in case of cynarases $\mathrm{A}$ and $\mathrm{C}$ and different from those of calf rennet, only the patterns resulted from using cynarases B was similar to those of calf rennet (Chazarra et al., 2007)

Coagulation activity strongly depends on the $\mathrm{pH}$ and temperature of milk (Chazarra et al., 2007). The optimum proteolytic activity of Cynaracran dunculuson on bovine casein occurred at pH range of 5.1 to 6.0 (Garcia et al., 2011). Llorente et al. (1997) also showed that crude extract of the (violet) part of mature flowers of Cynara scolymus L. illustrated an optimum clotting activity at acid $\mathrm{pH}$ ranged from 3.5 to 5.0 for bovine milk and low thermal stability at temperatures above $45^{\circ} \mathrm{C}$. Cynara scolymus protease exhibited maximum clotting activity at $70^{\circ} \mathrm{C}$ of cow milk (Sidrach et al., 2005). Rodrigues et al. (2009) also reported a maximum of milk clotting activity (MCA) of crude and purified extracts from Jacaratia corumbensis at $55^{\circ} \mathrm{C}$ using cow milk, while the optimum $\mathrm{pH}$ for crude and partially purified extracts was found to be 6.5 and 7.0, respectively.

\section{Rheological properties of curd}

Table 8 shows the water holding capacity (WHC \%) and susceptibility to syneresis (STS $\%$ ) of curd resulted from the artichoke protease of different extracts. Results showed different variations in both WHC (\%) and STS (\%) due to the different extraction buffer solutions. The best WHC (\%) and STS (\%) was observed in curd prepared using sodium phosphate buffer. 
Table 6. Effect of Glucono-Delta-Lactone (GDL) concentration on milk clotting activity using artichoke crude extracts

\begin{tabular}{|c|c|c|c|c|c|c|c|}
\hline \multirow[t]{2}{*}{ Treatment } & \multicolumn{6}{|c|}{ GDL concentration } & \multirow[t]{2}{*}{ Mean effect } \\
\hline & $0.0 \%$ & $0.1 \%$ & $0.2 \%$ & $0.3 \%$ & $0.4 \%$ & $0.5 \%$ & \\
\hline \multicolumn{8}{|c|}{ Clotting time (Sec.) } \\
\hline $\mathbf{T 1}$ & $1353.0^{\mathrm{a}}$ & $391.8^{\mathrm{cd}}$ & $308.4^{\text {cde }}$ & $210.0^{\text {cde }}$ & $252.6^{\text {cde }}$ & $330.0^{\text {cde }}$ & $474.30 \pm 419^{\mathrm{a}}$ \\
\hline $\mathbf{T} 2$ & $1165.8^{\mathrm{ab}}$ & $384.0^{\mathrm{cd}}$ & $209.4^{\text {cde }}$ & $197.4^{\text {cde }}$ & $196.8^{\text {cde }}$ & $194.4^{\text {cde }}$ & $391.30 \pm 363^{\mathrm{abc}}$ \\
\hline T3 & $1237.8^{a b}$ & $432.6^{\mathrm{c}}$ & $249.0^{\text {cde }}$ & $307.8^{\text {cde }}$ & $324.6^{\text {cde }}$ & $257.4^{\text {cde }}$ & $468.20 \pm 359^{\mathrm{ab}}$ \\
\hline T4 & $1045.8^{b}$ & $250.2^{\text {cde }}$ & $228.0^{\text {cde }}$ & $201.0^{\text {cde }}$ & $192.0^{\text {cde }}$ & $187.2^{\text {de }}$ & $350.70 \pm 320^{c}$ \\
\hline T5 & $1005.6^{b}$ & $306.0^{\text {cde }}$ & $189.6^{\mathrm{de}}$ & $195.6^{\text {cde }}$ & $206.4^{\text {cde }}$ & $197.4^{\text {cde }}$ & $350.10 \pm 304^{c}$ \\
\hline T6 & $1100.4^{b}$ & $251.4^{\text {cde }}$ & $248.4^{\text {cde }}$ & $200.4^{\text {cde }}$ & $215.4^{\text {cde }}$ & $205.2^{\text {cde }}$ & $370.20 \pm 336^{\mathrm{bc}}$ \\
\hline T7 & $1114.2^{\mathrm{ab}}$ & $312.6^{\text {cde }}$ & $138.6^{\mathrm{e}}$ & $191.4^{\text {cde }}$ & $189.0^{\text {de }}$ & $153.0^{\text {de }}$ & $349.80 \pm 494^{\mathrm{c}}$ \\
\hline T8 & $1185.6^{\mathrm{ab}}$ & $260.4^{\text {cde }}$ & $198.0^{\text {cde }}$ & $192.0^{\text {cde }}$ & $187.8^{\text {de }}$ & $202.2^{\text {cde }}$ & $371.00 \pm 375^{\mathrm{bc}}$ \\
\hline Mean effect & $1151.03 \pm 313^{\mathrm{A}}$ & $323.63 \pm 67.82^{\mathrm{B}}$ & $221.18 \pm 95.05^{C}$ & $211.95 \pm 37.43^{C}$ & $220.58 \pm 45.01^{\mathrm{C}}$ & $215.85 \pm 51.87^{\mathrm{C}}$ & 390.70 \\
\hline \multicolumn{8}{|c|}{$\mathrm{U} / \mathrm{ml}$ (unit of milk-clotting activity) } \\
\hline T1 & $17.74^{\mathrm{J}}$ & $61.26^{\mathrm{C}}$ & $77.82^{x}$ & $114.29^{n}$ & $95.01^{\mathrm{t}}$ & $72.73^{\mathrm{A}}$ & $73.14 \pm 30^{g}$ \\
\hline $\mathbf{T 2}$ & $20.59^{\mathrm{H}}$ & $62.50^{\mathrm{B}}$ & $114.61^{n}$ & $121.58^{\mathrm{hi}}$ & $121.95^{h}$ & $123.46^{\mathrm{f}}$ & $94.12 \pm 40^{\mathrm{e}}$ \\
\hline T3 & $19.39^{\mathrm{I}}$ & $55.48^{\mathrm{D}}$ & $96.39^{\mathrm{qr}}$ & $77.97^{\mathrm{wx}}$ & $73.94^{\mathrm{z}}$ & $93.24^{\mathrm{u}}$ & $69.40 \pm 26^{\mathrm{h}}$ \\
\hline T4 & $22.95^{\mathrm{F}}$ & $95.92^{\mathrm{rs}}$ & $105.26^{p}$ & $119.40^{j}$ & $125.00^{e}$ & $128.21^{\mathrm{c}}$ & $99.46 \pm 37^{c}$ \\
\hline T5 & $23.87^{\mathrm{E}}$ & $78.43^{w}$ & $126.58^{d}$ & $122.70^{\mathrm{g}}$ & $116.28^{\mathrm{m}}$ & $121.58^{\mathrm{hi}}$ & $98.24 \pm 38^{d}$ \\
\hline T6 & $21.81^{G}$ & $95.47^{\text {st }}$ & $96.62^{q}$ & $119.76^{\mathrm{j}}$ & $111.42^{\circ}$ & $116.96^{l}$ & $93.67 \pm 34$ \\
\hline T7 & $21.54^{\mathrm{G}}$ & $76.78^{\mathrm{y}}$ & $173.16^{\mathrm{a}}$ & $125.39^{e}$ & $126.98^{d}$ & $156.86^{b}$ & $113.45 \pm 52^{\mathrm{a}}$ \\
\hline T8 & $20.24^{\mathrm{H}}$ & $92.17^{\mathrm{v}}$ & $121.21^{\mathrm{i}}$ & $125.00^{\mathrm{e}}$ & $127.80^{c}$ & $118.69^{k}$ & $100.85 \pm 38^{\mathrm{b}}$ \\
\hline Mean effect & $21.02 \pm 1.88^{\mathrm{F}}$ & $77.25 \pm 15.54^{\mathrm{E}}$ & $113.96 \pm 27.29^{\mathrm{C}}$ & $115.76 \pm 14.97^{\mathrm{B}}$ & $112.30 \pm 18.05^{\mathrm{D}}$ & $116.47 \pm 23.68^{\mathrm{A}}$ & 92.79 \\
\hline \multicolumn{8}{|c|}{ RA\% (Relative activity) } \\
\hline T1 & $100.00^{\mathrm{A}}$ & $345.33^{u}$ & $438.72^{s}$ & $644.29^{n}$ & $535.63^{q}$ & $410.0^{t}$ & $412.33 \pm 174^{\mathrm{f}}$ \\
\hline $\mathbf{T} 2$ & $116.06^{\mathrm{yz}}$ & $352.34^{\mathrm{u}}$ & $646.13^{\mathrm{mn}}$ & $685.41^{\mathrm{h}}$ & $687.5^{\mathrm{gh}}$ & $695.99^{\mathrm{fg}}$ & $530.57 \pm 227^{e}$ \\
\hline T3 & $109.31^{\mathrm{zA}}$ & $312.76^{\mathrm{v}}$ & $543.37^{\mathrm{q}}$ & $439.57^{\mathrm{s}}$ & $416.82^{t}$ & $525.64^{r}$ & $391.25 \pm 151^{\mathrm{g}}$ \\
\hline T4 & $129.37^{\mathrm{wx}}$ & $540.77^{\mathrm{q}}$ & $593.42^{p}$ & $673.13^{j}$ & $704.69^{\mathrm{ef}}$ & $722.76^{c}$ & $560.69 \pm 208^{c}$ \\
\hline T5 & $134.55^{w}$ & $442.16^{\mathrm{s}}$ & $713.61^{\text {cde }}$ & $691.72^{\text {gh }}$ & $655.52^{\mathrm{lm}}$ & $685.41^{\mathrm{h}}$ & $553.83 \pm 214^{\mathrm{d}}$ \\
\hline T6 & $122.96^{\mathrm{xy}}$ & $538.19^{q}$ & $544.69^{q}$ & $675.15^{\mathrm{ij}}$ & $628.13^{\circ}$ & $659.36^{\mathrm{kl}}$ & $528.08 \pm 194^{\mathrm{e}}$ \\
\hline T7 & $121.43^{x y}$ & $432.82^{s}$ & $976.19^{a}$ & $706.90^{\text {de }}$ & $715.87^{\mathrm{cd}}$ & $884.31^{\mathrm{b}}$ & $639.59 \pm 295^{\mathrm{a}}$ \\
\hline T8 & $114.12^{\mathrm{yz}}$ & $519.59^{r}$ & $683.33^{\text {hi }}$ & $704.69^{\mathrm{ef}}$ & $720.45^{c}$ & $669.14^{\mathrm{jk}}$ & $568.55 \pm 220^{\mathrm{b}}$ \\
\hline Mean effect & $118.48 \pm 10.57^{\mathrm{F}}$ & $435.50 \pm 88.03^{\mathrm{E}}$ & $642.43 \pm 153^{\mathrm{C}}$ & $652.61 \pm 84.43^{\mathrm{B}}$ & $633.08 \pm 101^{\mathrm{D}}$ & $656.58 \pm 133^{\mathrm{A}}$ & 523.11 \\
\hline
\end{tabular}

Mean $( \pm$ SE). Values with small letters in the same column and values with capital letters in the row having different superscripts differ significantly $(\mathrm{p} \leq 0.05)$.

RA: Relative activity: Was calculated as $100 \%$ at without added GDL and increase or decrease according to clotting time (sec.).

T1=Distilled water, $\mathrm{T} 2=5 \% \mathrm{NaCl}$ in distilled water, $\mathrm{T} 3=5 \% \mathrm{NaCl}$ in sodium acetate buffer $(\mathrm{pH} 3.8$ ), $\mathrm{T} 4=5 \%$ $\mathrm{NaCl}$ in sodium acetate buffer $(\mathrm{pH} 5.0), \mathrm{T} 5=5 \% \mathrm{NaCl}$ in sodium phosphate buffer ( $\mathrm{pH} 5.5$ ), $\mathrm{T} 6=5 \% \mathrm{NaCl}$ in sodium phosphate buffer ( $\mathrm{pH} 6.5), \mathrm{T} 7=5 \% \mathrm{NaCl}$ in sodium phosphate buffer $(\mathrm{pH} 7), \mathrm{T} 8=5 \% \mathrm{NaCl}$ in Tris- $\mathrm{HCl}$ buffer (pH 8.0). 
Table 7. Proteolytic activity of crude extracts of artichoke during incubation time

\begin{tabular}{|c|c|c|c|c|c|c|c|}
\hline \multirow[t]{2}{*}{ Treatment } & \multicolumn{6}{|c|}{ Incubation time (hours) } & \multirow[t]{2}{*}{ Mean effect } \\
\hline & 1 & 2 & 3 & 4 & 5 & 6 & \\
\hline & \multicolumn{7}{|c|}{ Nonprotein nitrogen (NPN\%) } \\
\hline T1 & $0.04^{\mathrm{m}}$ & $0.07^{\mathrm{Im}}$ & $0.13^{\mathrm{k}}$ & $0.17^{\text {hij }}$ & $0.19^{\text {fghí }}$ & $0.2^{\text {efgh }}$ & $0.13 \pm 0.06^{\mathrm{d}}$ \\
\hline $\mathbf{T 2}$ & $0.05^{\mathrm{Im}}$ & $0.07^{\mathrm{Im}}$ & $0.14^{\mathrm{jk}}$ & $0.18^{\text {ghi }}$ & $0.2^{\text {efgh }}$ & $0.22^{\mathrm{def}}$ & $0.14 \pm 0.07^{\mathrm{cd}}$ \\
\hline T3 & $0.05^{\mathrm{Im}}$ & $0.07^{\mathrm{Im}}$ & $0.18^{\text {ghi }}$ & $0.22^{\text {def }}$ & $0.25^{\mathrm{cd}}$ & $0.28^{\mathrm{bc}}$ & $0.18 \pm 0.09^{b}$ \\
\hline T4 & $0.05^{\mathrm{Im}}$ & $0.08^{1}$ & $0.19^{\text {fghi }}$ & $0.21^{\text {efg }}$ & $0.27^{\mathrm{bc}}$ & $0.29^{\mathrm{ab}}$ & $0.18 \pm 0.09^{\mathrm{ab}}$ \\
\hline T5 & $0.05^{\mathrm{Im}}$ & $0.08^{1}$ & $0.19^{\text {fghi }}$ & $0.23^{\text {de }}$ & $0.28^{\mathrm{bc}}$ & $0.32^{\mathrm{a}}$ & $0.19 \pm 0.10^{\mathrm{a}}$ \\
\hline T6 & $0.05^{\mathrm{Im}}$ & $0.08^{1}$ & $0.18^{\text {ghi }}$ & $0.21^{\text {efg }}$ & $0.25^{\mathrm{cd}}$ & $0.28^{\mathrm{bc}}$ & $0.17 \pm 0.09^{b}$ \\
\hline T7 & $0.05^{\mathrm{Im}}$ & $0.08^{1}$ & $0.19^{\text {fghi }}$ & $0.23^{\text {de }}$ & $0.29^{\mathrm{ab}}$ & $0.32^{\mathrm{a}}$ & $0.19 \pm 0.10^{\mathrm{a}}$ \\
\hline T8 & $0.04^{\mathrm{m}}$ & $0.07^{\mathrm{Im}}$ & $0.16^{\mathrm{ijk}}$ & $0.19^{\text {fghi }}$ & $0.21^{\text {efg }}$ & $0.25^{\mathrm{cd}}$ & $0.15 \pm 0.08^{\mathrm{C}}$ \\
\hline \multirow[t]{2}{*}{ Mean effect } & $0.05 \pm 0.1^{\mathrm{F}}$ & $0.07 \pm 0.02^{\mathrm{E}}$ & $0.17 \pm 0.03^{\mathrm{D}}$ & $0.21 \pm 0.02^{\mathrm{C}}$ & $0.24 \pm 0.04^{\mathrm{B}}$ & $0.27 \pm 0.04^{\mathrm{A}}$ & 0.17 \\
\hline & \multicolumn{7}{|c|}{ (Non protein nitrogen/ Total nitrogen \%) NPN/TN (\%) } \\
\hline T1 & $7.55^{t}$ & $11.45^{\mathrm{r}}$ & $16.25^{\mathrm{q}}$ & $18.68^{\mathrm{p}}$ & $20.21^{\text {mno }}$ & $20.62^{\text {Imno }}$ & $15.79 \pm 4.95^{\mathrm{f}}$ \\
\hline T2 & $9.43^{\mathrm{s}}$ & $11.77^{\mathrm{r}}$ & $17.28^{\mathrm{q}}$ & $19.78^{\text {nop }}$ & $21.28^{\mathrm{klm}}$ & $22.68^{\mathrm{ij}}$ & $17.04 \pm 5.04^{\mathrm{e}}$ \\
\hline T3 & $9.43^{\mathrm{s}}$ & $11.77^{\mathrm{r}}$ & $21.69^{\mathrm{jkl}}$ & $24.18^{\mathrm{gh}}$ & $26.60^{\mathrm{e}}$ & $28.87^{\mathrm{cd}}$ & $20.42 \pm 7.53^{c}$ \\
\hline T4 & $9.43^{\mathrm{s}}$ & $12.1^{\mathrm{r}}$ & $22.89^{\mathrm{i}}$ & $23.08^{h i}$ & $28.72^{\mathrm{d}}$ & $29.90^{\mathrm{bc}}$ & $21.02 \pm 8.01^{\mathrm{b}}$ \\
\hline T5 & $9.43^{s}$ & $12.1^{\mathrm{r}}$ & $22.89^{\mathrm{i}}$ & $25.27^{\mathrm{fg}}$ & $29.79^{\text {bcd }}$ & $32.99^{\mathrm{a}}$ & $22.08 \pm 8.93^{\mathrm{a}}$ \\
\hline T6 & $9.43^{\mathrm{s}}$ & $12.1^{\mathrm{r}}$ & $21.69^{\mathrm{jkl}}$ & $23.08^{\mathrm{hi}}$ & $26.60^{\mathrm{e}}$ & $28.87^{\mathrm{cd}}$ & $20.30 \pm 7.39^{c}$ \\
\hline T7 & $9.43^{s}$ & $12.1^{\mathrm{r}}$ & $22.89 \mathrm{i}$ & $25.27^{\mathrm{fg}}$ & $30.85^{b}$ & $32.99^{\mathrm{a}}$ & $22.26 \pm 9.10^{\mathrm{a}}$ \\
\hline T8 & $7.55^{t}$ & $11.45^{\mathrm{r}}$ & $19.75^{\mathrm{op}}$ & $20.88^{\operatorname{lmn}}$ & $22.34^{\mathrm{ijk}}$ & $25.77^{\mathrm{ef}}$ & $17.96 \pm 6.55^{\mathrm{d}}$ \\
\hline Mean effect & $8.96 \pm 0.88^{\mathrm{F}}$ & $11.86 \pm 0.62^{\mathrm{E}}$ & $20.67 \pm 2.55^{\mathrm{D}}$ & $22.53 \pm 2.41^{\mathrm{C}}$ & $25.80 \pm 3.89^{\mathrm{B}}$ & $27.84 \pm 4.43^{\mathrm{A}}$ & 19.61 \\
\hline
\end{tabular}

Mean $( \pm \mathrm{SE})$. Values with small letters in the same column and values with capital letters in the row having different superscripts differ significantly $(\mathrm{p} \leq 0.05)$.

$\mathrm{T} 1=$ Distilled water, $\mathrm{T} 2=5 \% \mathrm{NaCl}$ in distilled water, $\mathrm{T} 3=5 \% \mathrm{NaCl}$ in sodium acetate buffer $(\mathrm{pH} 3.8), \mathrm{T} 4=5 \%$ $\mathrm{NaCl}$ in sodium acetate buffer ( $\mathrm{pH} 5.0$ ), $\mathrm{T} 5=5 \% \mathrm{NaCl}$ in sodium phosphate buffer ( $\mathrm{pH} 5.5$ ), $\mathrm{T} 6=5 \% \mathrm{NaCl}$ in sodium phosphate buffer ( $\mathrm{pH} 6.5$ ), $\mathrm{T} 7=5 \% \mathrm{NaCl}$ in sodium phosphate buffer ( $\mathrm{pH} 7$ ), $\mathrm{T} 8=5 \% \mathrm{NaCl}$ in $\mathrm{Tris}-\mathrm{HCl}$ buffer (pH 8.0).

Table 8. Effect of artichoke crude extracts on water holding capacity (WHC\%) and susceptibility to syneresis (STS \%)

\begin{tabular}{|c|c|c|c|c|c|c|c|c|c|}
\hline \multirow{2}{*}{$\begin{array}{l}\text { Enzyme con. } \\
\text { ml/100ml milk }\end{array}$} & \multicolumn{8}{|c|}{ Treatment } & \multirow[t]{2}{*}{ Mean effect } \\
\hline & T1 & T2 & T3 & T4 & T5 & T6 & T7 & T8 & \\
\hline & \multicolumn{9}{|c|}{ Water holding capacity (WHC \%) } \\
\hline 1 & $30.21^{\mathrm{c}}$ & $35.25^{b}$ & $27.24^{\mathrm{c}}$ & $49.24^{\mathrm{a}}$ & $50.32^{\mathrm{a}}$ & $49.25^{\mathrm{a}}$ & $49.14^{\mathrm{a}}$ & $47.56^{\mathrm{a}}$ & $42.28 \pm 9.54^{\mathrm{D}}$ \\
\hline 2 & $34.23^{\mathrm{c}}$ & $40.45^{\mathrm{bc}}$ & $30.33^{\mathrm{c}}$ & $51.23^{\mathrm{a}}$ & $54.56^{\mathrm{a}}$ & $52.25^{\mathrm{a}}$ & $53.11^{\mathrm{a}}$ & $50.45^{\mathrm{ab}}$ & $45.82 \pm 9.70^{\mathrm{C}}$ \\
\hline 3 & $44.23^{\mathrm{b}}$ & $48.34^{\mathrm{b}}$ & $36.61^{\mathrm{c}}$ & $63.26^{\mathrm{a}}$ & $67.41^{\mathrm{a}}$ & $63.5^{\mathrm{a}}$ & $64.12^{\mathrm{a}}$ & $63.35^{\mathrm{a}}$ & $56.35 \pm 11.24^{A}$ \\
\hline 4 & $43.23 b^{c}$ & $47.04^{b}$ & $37.13^{\mathrm{c}}$ & $58.37^{\mathrm{a}}$ & $63.34^{\mathrm{a}}$ & $59.48^{\mathrm{a}}$ & $58.46^{\mathrm{a}}$ & $57.51^{\mathrm{a}}$ & $53.51 \pm 9.36^{\mathrm{B}}$ \\
\hline 5 & $42.08^{\mathrm{C}}$ & $46.68^{\mathrm{bc}}$ & $34.01^{\mathrm{d}}$ & $50.81^{\mathrm{ab}}$ & $55.87^{\mathrm{a}}$ & $52.70^{\mathrm{ab}}$ & $51.81^{\mathrm{ab}}$ & $50.73^{\mathrm{ab}}$ & $48.09 \pm 7.23^{\mathrm{C}}$ \\
\hline \multirow[t]{2}{*}{ Mean effect } & $38.79 \pm 6.16^{\mathrm{D}}$ & $43.55 \pm 6.15^{\mathrm{C}}$ & $33.06 \pm 4.84^{\mathrm{E}}$ & $54.58 \pm 6.21^{\text {B }}$ & $58.30 \pm 7.3^{A}$ & $55.43 \pm 6.03^{\mathrm{AB}}$ & $55.32 \pm 6.16^{\mathrm{AB}}$ & $53.92 \pm 6.36^{\mathrm{B}}$ & $49.12 \pm 10.62$ \\
\hline & \multicolumn{9}{|c|}{ Susceptibility to syneresis (STS \%) } \\
\hline 1 & $45.5^{\mathrm{a}}$ & $42.22^{\mathrm{a}}$ & $47.25^{\mathrm{a}}$ & $45.24^{\mathrm{a}}$ & $41.24^{\mathrm{a}}$ & $43.25^{\mathrm{a}}$ & $42.11^{\mathrm{a}}$ & $43.52^{\mathrm{a}}$ & $43.79 \pm 3.63^{\mathrm{A}}$ \\
\hline 2 & $42.26^{\mathrm{a}}$ & $40.25^{\mathrm{a}}$ & $46.25^{\mathrm{a}}$ & $42.25^{\mathrm{a}}$ & $39.21^{\mathrm{a}}$ & $40.25^{\mathrm{a}}$ & $41.02^{\mathrm{a}}$ & $41.24^{\mathrm{a}}$ & $41.59 \pm 3.19^{\mathrm{AB}}$ \\
\hline 3 & $38.25^{\mathrm{a}}$ & $37.25^{\mathrm{a}}$ & $40.15^{\mathrm{a}}$ & $37.14^{\mathrm{a}}$ & $31.41^{\mathrm{a}}$ & $33.24^{\mathrm{a}}$ & $35.15^{\mathrm{a}}$ & $37.5^{\mathrm{a}}$ & $36.26 \pm 6.65^{\mathrm{C}}$ \\
\hline 4 & $41.11^{\mathrm{ab}}$ & $40.14^{\mathrm{abc}}$ & $42.55^{\mathrm{a}}$ & $39.25^{\mathrm{abc}}$ & $34.11^{\mathrm{c}}$ & $35.47^{\mathrm{bc}}$ & $39.12^{\mathrm{abc}}$ & $40.12^{\mathrm{abc}}$ & $38.98 \pm 3.39^{\mathrm{BC}}$ \\
\hline 5 & $45.12^{\mathrm{a}}$ & $44.42^{\mathrm{a}}$ & $46.32^{\mathrm{a}}$ & $45.23^{\mathrm{a}}$ & $39.24^{\mathrm{a}}$ & $40.33^{\mathrm{a}}$ & $43.24^{\mathrm{a}}$ & $44.57^{\mathrm{a}}$ & $43.56 \pm 3.63^{\mathrm{A}}$ \\
\hline Mean effect & $42.44 \pm 8.34^{\mathrm{AB}}$ & $40.85 \pm 3.17^{\mathrm{ABC}}$ & $44.50 \pm 3.88 \mathrm{~A}$ & $41.82 \pm 4.22 \mathrm{AB}$ & $37.04 \pm 4.82^{\mathrm{C}}$ & $38.50 \pm 4.63^{\mathrm{BC}}$ & $40.13 \pm 3.60^{\mathrm{ABC}}$ & $41.39 \pm 3.42^{\mathrm{ABC}}$ & C $\quad 40.84 \pm 5.11$ \\
\hline
\end{tabular}

Mean ( \pm SE). Values with small letters in the same column and values with capital letters in the row having different superscripts differ significantly $(\mathrm{p} \leq 0.05)$.

T1=Distilled water, $\mathrm{T} 2=5 \% \mathrm{NaCl}$ in distilled water, $\mathrm{T} 3=5 \% \mathrm{NaCl}$ in sodium acetate buffer $(\mathrm{pH} 3.8), \mathrm{T} 4=5 \%$ $\mathrm{NaCl}$ in sodium acetate buffer $(\mathrm{pH} 5.0), \mathrm{T} 5=5 \% \mathrm{NaCl}$ in sodium phosphate buffer ( $\mathrm{pH} 5.5$ ), $\mathrm{T} 6=5 \% \mathrm{NaCl}$ in sodium phosphate buffer ( $\mathrm{pH} 6.5$ ), $\mathrm{T} 7=5 \% \mathrm{NaCl}$ in sodium phosphate buffer $(\mathrm{pH} 7), \mathrm{T} 8=5 \% \mathrm{NaCl}$ in $\mathrm{Tris}-\mathrm{HCl}$ buffer (pH 8.0). 
The water holding capacity (WHC \%) of crude extracts of artichoke was significantly higher up to 3\%, then a slight reduction occurred when the concentration enzyme valued $4-5 \%$. Samples showed a higher level of water holding capacity and lower syneresis. These results confirmed by Fox et al. (2000), who reported a direct relationship between moisture and cheese firmness. Galán et al. (2008) reported that in relation to the attributes hardness and creaminess, cheeses produced with vegetable coagulant were significantly softer and more buttery than those using calf rennet. A negative correlation was found between cheeses hardness and soluble nitrogen and non protein nitrogen values in cheese made using vegetable coagulant. This may due to the higher proteolytic activity of casein breakdown. Moreover, the first degradations products may contribute to the softer and creamier texture compared to those produced by calf rennet.

The hydrophilic interactions reflecting the water holding capacity occurred between water and proteins play very important role in food systems influencing their flow and texture. Some of the intrinsic parameters could affect the water holding capacity of proteins influencing protein conformation, the chemical composition of amino acids and the polarity/ hydrophobicity of the proteins surface (Barbut, 1999). In addition, crude extracts of artichoke increasing the level of water holding capacity which resulted in the reduction of susceptibility to syneresis (STS\%). The lower STS (\%) may be explained by the high proteolytic activity (Table 7).

The use of the crude extracts of artichoke was found to be necessary to prevent serum separation, it could be noticed that increasing enzyme concentration decreased whey synersis up to $3 \%$, but increasing enzyme concentration up to $4-5 \%$, increased whey synersis. Syneresis, an undesirable property in crude extracts of artichoke, is the effect of liquid separating from the curd (Wu et al., 2001; Abd El-Gelil and ElZawahary, 2004).

\section{Conclusion}

Crude enzymatic extracts of bracts artichoke (Cynara scolymus) flower could be used as rennet substitute. The present study allowed evaluating the main characteristics of crude enzyme extracts, their coagulant and proteolytic activities and the different factors and coagulation parameters affecting these activities. A better understanding of extracted proteases properties was established for a better and future application in milk clotting $\mathrm{T} 4(5 \% \mathrm{NaCl}$ in sodium acetate buffer, $\mathrm{pH} 5.0)$ and $\mathrm{T} 5(5 \% \mathrm{NaCl}$ in sodium phosphate buffer, $\mathrm{pH} 5.5), \mathrm{T} 6$ (5\% $\mathrm{NaCl}$ in sodium phosphate buffer, $\mathrm{pH}$ 6.5), and T7 (5\% NaCl in sodium phosphate buffer, $\mathrm{pH}$ $7)$, respectively. Milk coagulation could be achieved using crude extracts of artichoke improving coagulation milk could be obtained at $\mathrm{pH}$ of $5.0-6.0$, and $65-70^{\circ} \mathrm{C}$ as temperature with a concentration of $3 \%, 0.4-0.05,3 \%, 0.5 \%$ of crude extract, $\mathrm{CaCl}_{2}, \mathrm{NaCl}$, and GDL, respectively. The whey synersis decreased by using crude enzyme concentration of $>3 \%$. Moreover, the best values of WHC (\%) and STS (\%) was observed in sodium phosphate buffer solutions (T5, T6, T7) and sodium phosphate buffer (T4).

\section{REFERENCES}

Abd El-Gelil, A. A. and A. R. El- Zawahary (2004). Milk clotting enzyme by using Solanum dobium plant as rennet substitute, 1Preliminary studies on the enzyme extract from Solanum dobium plant on milk clotting. Zagazig J. Agric. Res., 6: 2999-3017.

Ahmed, I.A.M., I. Morishima, E.E. Babiker and N. Mori (2009). Characterization of partially purified milk clotting enzyme from Solanum dubium Fresen seeds. Food Chem., 116: 395400.

Bah, S., B.S. Paulsen, D. Diallo and H.T. Johansen (2006). Characterization of cysteine proteases in Malian medicinal plants. J. Ethnopharmacol, 107: 189-198.

Barbut, S. (1999). Determining Water and Fat Holding. In G. M. Hall (Ed.), Methods of (pp. 186-225). New York: Blackie Academic and Professional.

Bencini, R. (2002). Factors affecting the clotting properties of sheep milk. J. Sci. Food Agric., 82: 705-719.

Cabezas, L., M.A. Esteban and A. Marcos (1981). Agar gel diffusion of Cynara humilis 
L. proteinases and other enzymes. Alimentaria, 128: 17-22.

Campos, R., R. Guerra, M. Aguilar, O. Ventura and L. Camacho (1990). Chemical characterization of proteases extracted from wild thistle (Cynara cardunculus). Food Chem., 35: 89-97.

Cattaneo, T.M., F. Nigro, G. Messina and M. Giangiacomo (1994). Effect of an enzymatic complex from pineapple pulp on the primary clotting phase. Milchwissenschaft, 49: 269272.

Chazarra, S., L. Sidrach, D. López-Molina and J.N. Rodríguez- López (2007). Characterization of the milk-clotting properties of extracts from artichoke (Cynara scolymus, L) flowers. Int. Dairy J., 17:1393-1400.

Chen, S., J. Zhao and S. Agboola (2003). Isolation and partial characterization of rennet-like proteases from Australian cardoon (Cynara cardunculus L.) J. Agric. Food Chem., 51: 3127-3134.

Cochran, W.G. and G.M. Cox (1992). Experimental Designs ( $2^{\text {nd }} E d$.). New York, NY: John Wiley and Sons.

Cordeiro, M., E. Jakob, Z. Puhan, M.S. Pais and P.E. Brodelius (1992). Milk clotting and proteolytic activities of purified cynarases from Cynara cardunculus a comparison to chymosm. Milchwissenschaft, 47: 683-687.

Cordeiro, M., M.S. Pais and P.E. Brodelius, (1998). In: Bajaj YPS (ed) Biotechnology in Agriculture and Forestry. Springer, Heidelberg.

Domingos, A., P.C. Cardos, Z.T. Xue, A. Clemente, P.E. Brodelius and M.S. Pais (2000). Purification, cloning and autoproteolytic processing of an aspartic proteinase from Centaurea calcitrapa. Eur. J. Biochem., 267: 6824-6831.

El-Abbassy, F. (1977). Studies on Milk Clotting Enzymes and their Application in the Manufacture of Domiati Cheese. Ph.D. Thesis, Fac. Agric., Alex. Univ.

El-Shibiny, S., H.M. Abd El-Salam, I.D. Rifaat and H.A. Fahmi (1973). Studies on milk clotting enzyme from plant source. II. Separation of milk clotting enzymes from latex of Ficus carica var. soltani. J. Food Sci. Technol., 5: 30-34.

Esposito, M., P. Di Pierro, W. Dejonghe, L. Mariniello and R. Porta (2016). Enzymatic milk clotting activity in artichoke (Cynara scolymus) leaves and alpine thistle (Carduus defloratus) flowers. Immobilization of alpine thistle aspartic protease. Food Chem., 204: 115-121.

Fox, P.F., T.P. Guinee, T.M. Cogan and P.L.H. McSweeney (2000). Cheese Rheology and Texture, In Fundamental of Cheese Science, Aspen Pub., USA, 305-342.

Fuquay, J.W., P.F. Fox and P.L.H. McSweeney (2011). Encyclopedia of Dairy Sciences $\left(2^{\text {nd }}\right.$ Ed.). 632. Academic Press is an imprint of Elsevier, Jamestown, London, UK.

Galán, E., F. Prados, A. Pino, L. Tejada and J. Fernandez-Salguero (2008). Influence of different amounts of vegetable coagulant from cardoon Cynara cardanculus and calf rennet on the proteolysis and sensory characteristics of cheeses made with sheep milk. Int. Dairy J., 18: 93-98.

Garcia, H.S., A.L. Hernandez and C.G. Hill (2011). Enzyme technology dairy industry applications. Comprehensive Biotechnol., 4: 567-574.

Guiama, V. D., D. G. Libouga, E. Ngah and C. M. Mbofung (2010). Milk clotting activity of berries extracts from nine Solanum plants. Afr. J. Biotech., 9: 3911-3918.

Gupta, B.C. and M.A.N. Eskin (1977). Potential use of vegetable rennet in the production of cheese. Food Technol., 31: 62-65.

Hashim, M.M., D. Mingsheng, M.F. Iqbal and C. Xiaohong (2011). Ginger rhizome as a potential source of milk coagulating cysteine protease. Phytochem., 72: 458-464.

Heimgartner, U., M. Pietrzak, R. Geertsen, P. Brodelius, A.C. Da Silva Figueiredo and M.S.S. Pais (1990). Purification and partial characterization of milk clotting proteinases from flowers of Cynara cardunculus. Phytochem., 29: 1405-1410.

Horne, D.S. and C.M. Davidson (1993). In protein and fat globule modifications by heat 
treatment, homogenization and other technological means for high quality dairy products. Int. Dairy Federation Brussels, 9303: 267-276.

Huang, X.W., L.J. Chen, Y.B. Luo, H.Y. Guo, and F.Z. Ren (2011). Purification, characterization and milk coagulating properties of ginger proteases. J. Dairy Sci., 94: 2259-2269.

Isanga, J. and G. Zhang (2009). Production and evaluation of some Physicochemical parameters of peanut milk yoghurt. LWT Food Sci. and Technol., 42: 1132-1138.

Lagaude, A., L. Femandez, J.L. Cuq and S. Marchesseau (2004). Characterization of curd formation during the rennet coagulation of milk by an optical microscopic method. Int. Dairy J., 14: 1033-1039.

Liorente, B.E., W.D. Obregón, F.X. Avilés, N.O. Caffini and S. Vairo-Cavalli (2014). Use of artichoke (Cynara scolymus) flower extract as a substitute for bovine rennet in the manufacture of Gouda-type cheese: Characterization of aspartic proteases. Food Chem., 159: 55-63.

Llorente, B.E., C.B. Brulti, C, L. Natalucci and Y.O. Caffini (1997). Partial characterization of a milk clotting proteinase isolated from Artichoke (Cynara Scolymus L., Asteraceae). Acta Farmaceutica Bonaerense, 16: 37-42.

Llorente, B.E., C.B. Brutti and N.O. Caffini (2004). Purification and characterization of a milk-clotting aspartic proteinase from globe artichoke (Cynara scolymus L.). J. Agric. Food Chem., 52: 8182-8189.

Lo Piero, A.R., G. Petrone and I. Puglisi (2002). Characterization of lettucine, a serine like protease from Lactuca sativa leaves, as a novel enzyme for milk-clotting. J. Agric. Food Chem., 50: 2439-2443.

Magdoub, M.N., N. Sultan, N. Hegazi and A.E. Shehata (1984). Effect of adding calcium chloride to the rennet on milk clotting activity. Asian J. Dairy Res., 2: 218-220.

Mohan, C. (2006). Buffers a guide for the preparation and use of buffers in biological systems. EMD Biosciences, Inc., EMD, an affiliate of Merck KGaA, Darmstadt, Germany.
Najera, A.L., M. Renobales and L.R. Barron (2003). Effects of $\mathrm{pH}$, temperature, $\mathrm{CaCl}_{2}$ : and enzyme concentrations on the rennetclotting properties of milk: A multifactorial study. Food Chem., 80: 345-352.

Nouani, A., E. Dako, A. Morsli, N. Belhamiche, S. Belbraouet, M.M. Belial and A. Dadie (2009). Characterization of the purified coagulant extracts derived from artichoke flowers (Cynara scolymus) and from the fig tree Latex (Ficus carica) in light of their use in the manufacture of traditional cheeses in Algeria. J. Food Technol., 7: 20-29.

Nunez, M., B. Fernandez del Pozo, M. Rordriguez-Marin and P. Gaya (1991). Effect of vegetable and animal rennet on chemical, microbiological and sensory characteristics of La Serena cheese. J. Dairy Res., 58: 511519.

Raposo, S. and A. Domingos (2008). Purification and characterization milk-clottmg. Aspartic proteinases from Centaurea calcitrapa cell suspension cultures. Process Biochem., 43: 139-144.

Rodrigues, A.D., M.R. Bebora, A.M. Keila, L.F. Maria, T.H. Jose Lusi and L.A. Ana (2009). Jacaratia corumbensis O. Kuntze a new vegetable source for milk-clotting enzymes. Brazilian Archive Biolo. Technol., 52: 1-9.

Shah, M. A., S. A. Mir and M. A. Paray (2014). Plant proteases as milk-clotting enzymes in cheese making: A review. Dairy Sci. and Technol., 94: 5-16.

Sidrach, L., F. Garcia-Canovas, J. Tudela and J. Rodriguez-Lopez (2005). Purification of cynarases from artichoke (Cynara scolymus L.): enzymatic properties of cynarase A. Phytochem., 66: 41-49.

Silva, S.V. and F.X. Malcata (1999). On the activity and specificity of cardosin B, a plant proteinase, on ovine caseins. Food Chem., 67: 373-378.

Silva, S.V., R.M. Barros and F.X. Malcata (2002). Hydrolysis of caseins by extracts of Cynara cardunculus precipited by ammonium sulphate. J. Food sci., 67: 17461751. 
Simoes, I. and C. Faro (2004). Structure and function of plant aspartic proteinases. Eur. J. Biochem., 271: 2067-2075.

Verissimo, P., M. Ramalho-Santos, C. Faro, E. Pires (1998). A comparative study on the aspartic proteinases from dierent species of cynara. Advances in Experim. Med. and Biol., 436: 459-463.
Wu, H., G.J. Hulbert and J.R. Mount (2001). Effects of ultrasound on milk homogenization and fermentation with yogurt starter. Innovative Food Sci. and Emerg. Technol., 1: 211-218.

Zhao, Z. and M. Corredig (2016). Influence of sodium chloride on the colloidal and rennet coagulation properties of concentrated casein micelles suspensions. J. Dairy Sci., 99:1-10.

\title{
تقييم مستخلصات بديل المنفحة المستخلص من أزهار الخرشوف (Cynara scolymus): دراسة العوامل المؤثرة على القرة التجبنية للبن الترين
}

\author{
هبة الله حلمي عبد الرووف ـ أحمد علاء الدين النشوي ـ عبد الحميد محمد ربيع - صلاح أحمد خليفة

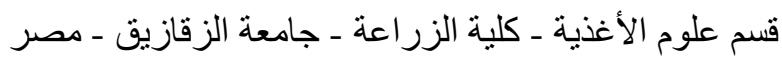

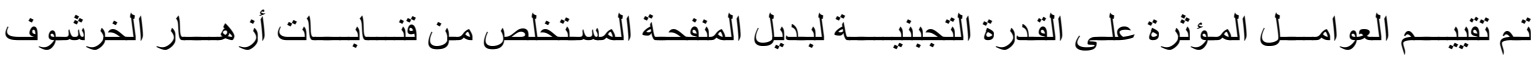

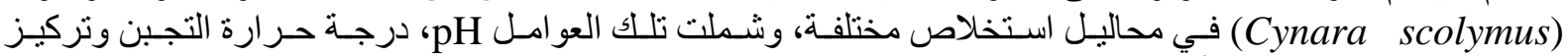

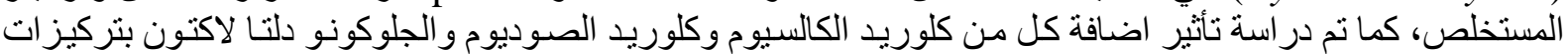

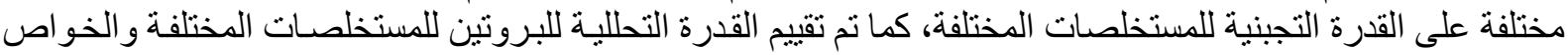

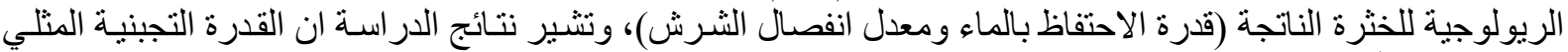

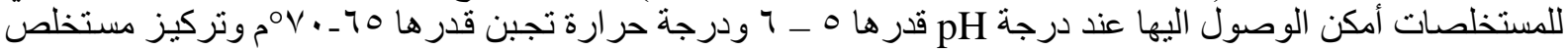

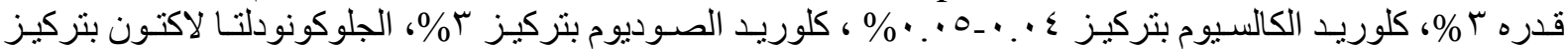

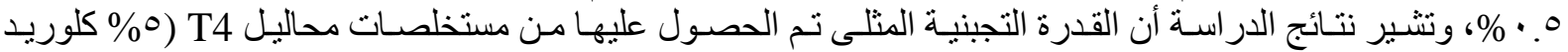

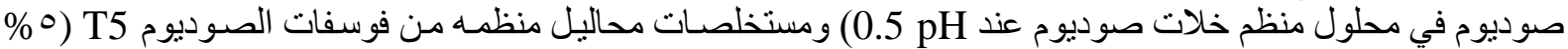

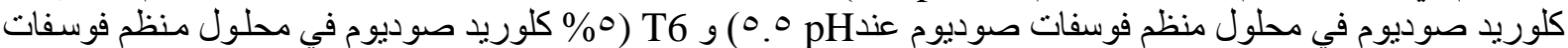

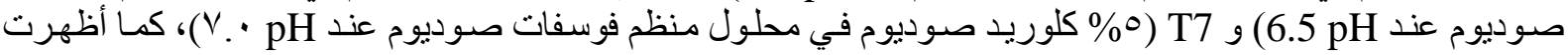

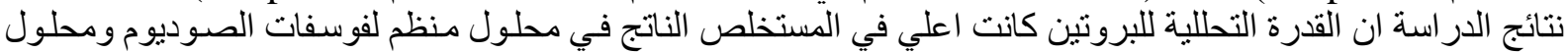

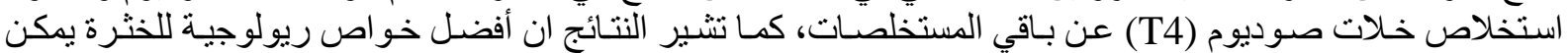

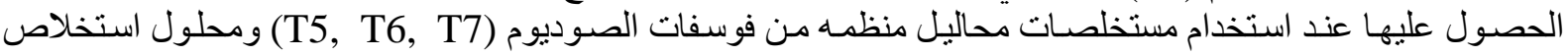

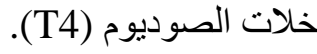

أستاذ الألبان - كلية الزراعة - جامعة عين شمس.

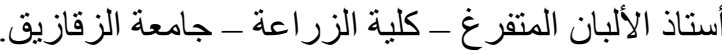

